\title{
ResearchOnline@JCU
}

This is the author-created version of the following work:

Sher, Judd, Miller, Catherine M., and Sharma, Dileep (2020) Effect of bisphosphonates on the osteogenic activity of osteoprogenitor cells cultured on titanium surfaces. International Journal of Oral \& Maxillofacial Implants, 35 (5) pp. 939-947.

Access to this file is available from: https://researchonline.jcu.edu.au/62954/

(C) 2020 BY QUINTESSENCE PUBLISHING CO, INC. PRINTING OF THIS DOCUMENT IS RESTRICTED TO PERSONAL USE ONLY. NO PART MAY BE REPRODUCED OR TRANSMITTED IN ANY FORM WITHOUT WRITTEN PERMISSION FROM THE PUBLISHER. Authors can share their reviewed and accepted (postprint) manuscript via noncommercial platforms, such as their institutional repository, after a 12-month embargo period.

Please refer to the original source for the final version of this work: 
The International Journal of Oral \& Maxillofacial Implants

\begin{tabular}{|l|l|}
\hline Manuscript: & JOMI-2020-73/R3 RESUBMISSION - (8354) \\
\hline Title: & $\begin{array}{l}\text { Effect of Bisphosphonates on the Osteogenic Activity of } \\
\text { Osteoprogenitor Cells Cultured on Titanium Surfaces }\end{array}$ \\
\hline Keywords: & $\begin{array}{l}\text { Alendronate, Bisphosphonates, Dental Implants, Osseointegration, } \\
\text { Osteoblasts, Zoledronate }\end{array}$ \\
\hline Type: & Experimental \\
\hline
\end{tabular}


Effect of Bisphosphonates on the Osteogenic Activity of Osteoprogenitor Cells

\section{Cultured on Titanium Surfaces}

Dr Judd Sher ${ }^{1}$, BDS. Dr Catherine Miller ${ }^{2}$ BSc(Hons) PhD. Dr Dileep Sharma ${ }^{1}$, BDS MDS(Perio) $\mathrm{PhD}$.

${ }^{1}$ College of Medicine \& Dentistry, James Cook University, 14-88 McGregor Road, Smithfield, QLD 4878, Australia.

${ }^{2}$ College of Public Health, Medical and Veterinary Sciences, James Cook University, 14-88 McGregor Road, Smithfield, QLD 4878, Australia.

\section{Corresponding Author:}

Dileep Sharma

Phone: +61 410462827

Email: dileep.sharma@jcu.edu.au

Journal:

Manuscript prepared for 'The International Journal of Oral \& Maxillofacial Implants (JOMI)' 


\section{Effect of Bisphosphonates on the Osteogenic Activity of Osteoprogenitor Cells}

\section{Cultured on Titanium Surfaces}

\section{ABSTRACT}

Purpose: This study investigated the effects of bisphosphonates (BPs) namely Alendronate (ALN) and Zoledronate (ZA) on the osteogenic activity of osteoprogenitor cells cultured on titanium surfaces at therapeutic doses in order to assess if altered osteoblastogenesis could compromise osseointegration and contribute in etiopathogenesis of painful disorders like BPrelated Osteonecrosis of the Jaw (BRONJ) following implant placement. Materials and Methods: MC3T3-E1 Subclone 4 cells were utilised in this study. Therapeutic doses of ALN and ZA were calculated based off reported peak plasma concentrations. The viability, proliferation, adhesion, and mineralisation potential of cells was assessed using a LIVE/DEAD stain, alamarBlue ${ }^{\circledR}$ assay, immunofluorescence microscopy, and Alizarin Red S staining respectively. Results: Therapeutic doses of ZA negatively affected cell viability, whereas therapeutic doses of ALN significantly enhanced cell differentiation and the amount of bone formation compared to the control. Conclusions: The findings of this study may provide some insight into the pathogenesis of BRONJ developing following implant placement in patients treated with ZA and may have promising implications towards improved wound healing and osseointegration in patients treated with ALN.

Keywords: Alendronate, Zoledronate, Bisphosphonates, Osseointegration, Osteoblasts, Dental Implants 


\section{INTRODUCTION}

Bone healing around modern titanium-based dental implants involves a complex chain of biological events that results in predictable osseointegration. ${ }^{1}$ Osteogenesis begins early in this process, approximately four days after placement of the implant, and continues for a further three months until bone-implant contact is achieved. ${ }^{2}$ During osteogenesis, viable osteoprogenitor cells in the granulation tissue differentiate into the bone-forming osteoblasts and deposit osteoid and minerals towards, and on, the implant surface. ${ }^{3}$

Bisphosphonates (BPs) are a group of anti-resorptive agents that are widely used to treat a variety of diseases characterised by excessive bone resorption, such as osteoporosis, multiple myeloma, Paget's disease, hypercalcemia of malignancy, and cancer bone metastasis. These drugs significantly improve patient's quality of life by preventing events such as fractures and limiting bone pain and metastatic spread. ${ }^{4}$ In addition to their inhibitory effects on osteoclasts, BPs have been shown to affect several other cells, including epithelial cells, lymphocytes, macrophages, myelomas, and breast cancer cells. Furthermore, the mechanism of action of these drugs on bone may not be completely understood. ${ }^{5}$ Recent studies suggest that based on the type of BPs used and the multiple experimental protocols, BPs may also have a direct action on the bone forming capabilities of osteoblasts. ${ }^{6}$

BPs, due to their association with the a osseo-destructive condition called Medication-related Osteonecrosis of the Jaw (MRONJ) have been extensively studied in recent literature. ${ }^{7,8}$ MRONJ is characterised by exposed necrotic bone in the maxillofacial region that has 
persisted for more than eight weeks in patients with a history of treatment with antiresorptive or anti-angiogenic drug therapy, and where there has been no history of radiation therapy to the jaw or no obvious metastatic disease to the jaws. Dentoalveolar surgery is considered a major risk factor for developing MRONJ, including the procedure of placing dental implants. Several hypotheses have been proposed to explain the delayed bone healing seen in MRONJ; however, it is likely that the cause of the disease is multi-factorial, with each of the drugs having slightly different etiopathogenic mechanisms. ${ }^{9}$ Since only BPs are used in this study, we use the term BP-related Osteonecrosis of the Jaw (BRONJ) instead of MRONJ.

Osteogenesis is an integral part of hard tissue healing around dental implants and it is well accepted that BP therapy could induce predisposition for premature loss of implant and BRONJ. While Alqhtani et al. ${ }^{10}$ previously reported that low doses of BPs (less than 1000th of clinical doses) could enhance the osteogenic activity in vitro, it is not known if similar effects are observed with therapeutic doses of BPs. With this in mind, the aim of this in vitro study was to investigate how therapeutic doses of BPs could affect viability, proliferation, adhesion, and differentiation of osteoprogenitor cells cultured on titanium surfaces.

2 METHODS

\subsection{Cell culture}

MC3T3-E1 Subclone 4 (ATCC ${ }^{\circledR}$ CRL2593 $^{\text {TM}}$; Manassas, VA, USA) - mouse calvarium-derived osteoprogenitor cells were utilised in this study. Cells were expanded at $37^{\circ} \mathrm{C}$ with complete 
growth media (CGM) comprising of Dulbecco's Modified Eagle's Medium (DMEM) admixed with 10\% Foetal Calf Serum (FCS) and 1\% Penicillin-Streptomycin (Sigma-Aldrich, Castle Hill, NSW, Australia) placed within a $5 \% \mathrm{CO}_{2}$ incubator. The media was replenished every $4^{\text {th }}$ day and cells were passaged at $95 \%$ confluence as confirmed using an inverted microscope (Nikon Eclipse TS100, Nikon Instruments Incorporated, Melville, NY, USA) (Fig. 1). Only cells from passages 3 to 9 were used in the experiments and all experiments were conducted using triplicate sampling protocol.

2.2 Titanium disc preparation

Commercially pure titanium discs (14 mm x $3.5 \mathrm{~mm}$ ) (Fig. 2), were placed into the wells of 12well tissue-culture plates (one disc per well). Prior to the first experiment, the titanium discs were roughened with a sandblaster for 3-minutes (150-200 $\mu$ m alumina particles) (Korox 110, BEGO, Bremen, Germany). Between the experiments, the titanium discs were physically cleaned using a soft nylon brush, placed in an ultrasonic bath for 30-minutes, rinsed with ultrapure water (Milli-Q), and then sterilised in an autoclave at $134{ }^{\circ} \mathrm{C}$ for 20 -minutes.

\subsection{Experimental groups}

Two commonly prescribed BPs were assessed, Alendronate (ALN) and Zoledronate (ZA; Sigma-Aldrich, Castle Hill, NSW, Australia), at concentrations equivalent to their respective therapeutic doses (Table 1). These drug concentrations were based on reported human plasma concentrations attained after administering a single therapeutic dose of oral ALN (70 
$\mathrm{mg}$ ) or intravenous ZA (2-4 mg). ${ }^{11,12}$ To further investigate whether there was a direct correlation between the potency of BPs and their effects on the cells, half of these concentrations were also used.

\subsection{Stock solutions}

Stock solutions were prepared by dissolving ALN and ZA in phosphate-buffered saline (PBS) at $\mathrm{pH} 7.2$ and storing at $-20^{\circ} \mathrm{C}$. Osteogenic media (OM) was prepared according to Sharma et al. and comprised of CGM supplemented with $\beta$-glycerophosphate $(10 \mathrm{mM})$, ascorbic acid $(200 \mu \mathrm{M})$ and dexamethasone $(100 \mathrm{nM}) .{ }^{8}$ Prior to the experiments, $\mathrm{ALN}$ and ZA solutions were diluted with CGM or OM to the above mentioned concentrations.

\subsection{Cell viability}

Cells were seeded onto the titanium discs (200 $\mu \mathrm{L} @ 1 \times 10^{6}$ cells $\left./ \mathrm{mL}\right)$ in CGM and left to attach for 30 -minutes in an incubator at $37{ }^{\circ} \mathrm{C}$ with $5 \% \mathrm{CO}_{2}$. Wells were then topped up with $\mathrm{CGM}$ containing cells (1.4 mL @ 3.25 $\times 10^{5}$ cells $/ \mathrm{mL}$ ) and cells were incubated for an additional day. To ensure that cells attached to the walls of tissue well plates did not influence the experimental findings, the titanium discs were moved to a fresh 12-well tissue-culture plates on the subsequent day. CGM supplemented with the different concentrations of ALN or ZA was then added to the wells ( $1.6 \mathrm{~mL}$ per well) and refreshed every 3 days. Viability of cells was assessed at the end of days 3 and 10 using LIVE/DEAD stain. Titanium discs were moved to 6-well tissue-culture plates ( 3 discs per well). A working solution of $20 \%$ CytoPainter (ab219941; Abcam, Melbourne, VIC, Australia) and 2\% Propidium lodide (P1304MP; Thermo 
Scientific, Rockford, IL, USA) in PBS was used at (.4 mL/well. Cells were incubated at $37^{\circ} \mathrm{C}$ and refrigerated at $4^{\circ} \mathrm{C}$ for $0.5 \mathrm{hr}$ each and washed with PBS (twice)before fluorescence was visualised using an Olympus IX53 inverted epi-fluorescence microscope (Olympus Australia Pty Ltd, Mount Waverley, VIC, Australia).

\subsection{Cell proliferation}

Cells were seeded onto the titanium discs ( $200 \mu \mathrm{L} @ 1 \times 10^{6}$ cells $\left./ \mathrm{mL}\right)$ in CGM and left to attach for 30-minutes in an incubator at $37^{\circ} \mathrm{C}$ with $5 \% \mathrm{CO}_{2}$. Wells were then topped up with $\mathrm{CGM}$ containing cells (1.4 mL @ 3.25 $\times 10^{5}$ cells $/ \mathrm{mL}$ ) and cells were incubated for an additional day. The next day, the titanium discs were moved to a fresh 12-well tissue-culture plates and CGM supplemented with the different concentrations of ALN or ZA was added to the wells $(1.6 \mathrm{~mL}$ per well) and refreshed every 3 days. Proliferation of cells was assessed at the end of days 3 , 6 and 10 using the alamarBlue ${ }^{\circledR}$ assay. A $10 \%$ v/v dye solution of resazurin sodium salt (SigmaAldrich, Castle Hill, NSW, Australia) was added into each well and cells were incubated for 5hours at $37{ }^{\circ} \mathrm{C}$ with $5 \% \mathrm{CO}_{2} .100 \mu$ l aliquots of media were then transferred into a 96-well clear plate to measure the absorbance values from test and control wells at $600 \mathrm{~nm}$ and $570 \mathrm{~nm}$ (Bio-Rad Laboratories Pty Ltd, Gladesville, NSW, Australia). The proportion of viable cells and the proliferation rate was determined by calculating the percentage of reduction of alamarBlue $^{\circledR}$ reagent within each well. 


\subsection{Cell adhesion}

Cells were seeded in CGM onto the titanium discs ( $200 \mu \mathrm{L} @ 5 \times 10^{5}$ cells $/ \mathrm{mL}$ ) and left to attach for 30-minutes in an incubator at $37{ }^{\circ} \mathrm{C}$ with $5 \% \mathrm{CO}_{2}$. Wells were then topped up with $\mathrm{CGM}$ supplemented with the different concentrations of ALN or ZA (1.4 mL per well) and cells were incubated for an additional day. The next day, after PBS wash, the cells were fixed for 10minutes at room temperature with $4 \%$ paraformaldehyde. Cells were then permeabilised using $0.05 \%$ TWEEN $^{\circledR} 20$ (Sigma-Aldrich, Castle Hill, NSW, Australia) for 10-minutes at room temperature. Following this, cells were blocked with 5\% FBS for 30-minutes at room temperature. Cells were then stained with Flash Phalloidin ${ }^{\mathrm{TM}}$ Red (BioLegend, San Diego, California, USA) and 4',6-Diamidino-2-Phenylindole (DAPI) (BioLegend, San Diego, California, USA) for 20-minutes at room temperature. Fluorescence was visualised and imaged using an Olympus IX53 inverted epi-fluorescence microscope (Olympus Australia Pty Ltd, Mount Waverley, VIC, Australia). Images were collected and processed using ImageJ software (U. S. National Institutes of Health, Bethesda, Maryland, USA) and quantitative analysis was performed by calculating the corrected total cell fluorescence of F-actin in three isolated cells per group using the same software.

\subsection{Mineralisation}

Cells were seeded in CGM onto the titanium discs (200 $\mu \mathrm{L} @ 1 \times 10^{6}$ cells $\left./ \mathrm{mL}\right)$ and left to attach for 30 -minutes in an incubator at $37^{\circ} \mathrm{C}$ with $5 \% \mathrm{CO}_{2}$. Wells were then topped up with $\mathrm{CGM}$ containing cells (1.4 mL @ $1 \times 10^{6}$ cells $/ \mathrm{mL}$ ) and cells were incubated for an additional day. The next day, the titanium discs were moved to fresh 12-well tissue-culture and OM 
supplemented with the ALN or ZA was then added to the wells (1.6 mL per well) that was refreshed every 4-days. Mineralisation was assessed on day 14 using Alizarin Red S staining as previously described by Reinholz et al. ${ }^{5}$ Briefly, medium was aspirated from the wells and cells were rinsed twice with PBS at room temperature and once with ice-cold PBS. Cells were then fixed with ice-cold $70 \%(\mathrm{v} / \mathrm{v})$ ethanol for 1-hour. The ethanol was discarded and cells were rinsed twice with deionised water. $40 \mathrm{mM}$ Alizarin Red S (Sigma-Aldrich, Castle Hill, NSW, Australia) in deionised water (adjusted to $\mathrm{pH} 4.2$ ) was then added to stain the cells for 10-minutes at room temperature. Next, the Alizarin Red S solution was discarded and titanium discs were placed in new 12-well tissue-culture plates. Cells were rinsed 5 times with deionised water and then incubated in PBS for 15-minutes at room temperature on a Grant ES-20 Compact Shaker-Incubator orbital rotator (150 rpm; VWR International, Pty Ltd, Tingalpa, QLD, Australia). The PBS was then discarded and cells were rinsed once with fresh PBS before being de-stained with $10 \%(\mathrm{w} / \mathrm{v})$ cetylpyridinium chloride in $10 \mathrm{mM}$ sodium phosphate ( $\mathrm{pH} 7.0)$ for 15 -minutes at room temperature on an orbital rotator (150 rpm). The extracted stain was then transferred to a 96-well clear plate to measure absorbance at 570 nm (Bio-Rad Laboratories Pty Ltd, Gladesville, NSW, Australia).

\subsection{Statistical analysis}

All the acquired data were expressed as mean \pm standard deviation. Comparisons were between the experimental groups and the control and were conducted using analysis of variance (ANOVA, two-tailed, post hoc test: Dunnett). The software SPSS 25.0 for windows (IBM, St Leonards, NSW, Australia) was used for calculations and results with $p$ less than 0.05 was considered to be statistically significant. 


\section{RESULTS}

\subsection{Cell viability}

The viability assay acted as a preliminary experiment to identify the cytotoxic effects of the BPs on the cells at the selected drug concentrations. After 3 days of incubation no cytotoxic effects were observed, as titanium discs were almost completely confluent with live cells in all groups (Fig. 3). By day 10 of culture however, cytotoxic effects were evident in the groups treated with therapeutic doses of ZA. This negative effect that ZA had on cellular viability was found to be dose and time dependent as notably more dead cells were present with the therapeutic dose compared with the half dose and after 10 days compared to that after 3 days.

\subsection{Cell proliferation}

The proliferation assay aimed to investigate the effects of ALN and ZA on cell division and growth using the alamarBlue ${ }^{\circledR}$ assay. Cells followed a typical growth curve in all the experimental groups, where the number of cells slightly decreased from day 3 to day 6 before reaching a maximum at the end of day 10 (Fig. 4). Both doses of ALN and the therapeutic dose of ZA significantly inhibited cell proliferation after 3 days (control $24.52 \% \pm 0.77 \%$, ALN 0.1 $\mu \mathrm{M} 22.97 \% \pm 0.23 \%$, ALN $0.2 \mu \mathrm{M} 22.87 \% \pm 0.92 \% \&$ ZA $1 \mu \mathrm{M} 22.74 \% \pm 0.48 \%, p=0.280, p=$ $0.020 \& p=0.013)$, however there were no significant effects on cell proliferation observed 
thereafter. Half the therapeutic dose of ZA showed no significant effects on cell proliferation throughout the 10 days of culture.

\subsection{Cell adhesion}

The adhesion assay aimed to investigate the effects of ALN and ZA on cell attachment to the titanium disc using immunofluorescence microscopy to study the cytoskeletal protein F-actin. After 24-hours, no observable differences in cell morphology and spread were evident and this was confirmed with statistical analysis where the amount of F-actin expression per viable cell was not significantly different between the groups and the control (Fig. 5 \& Fig 6).

\subsection{Mineralisation}

The mineralisation assay aimed to investigate the effects of ALN and ZA on cell differentiation and subsequent mineralisation using Alizarin Red S staining. At the end of 14-days, ALN at both doses was found to significantly promote mineralisation compared to the control (control $0.081 \pm 0.009$, ALN $0.1 \mu \mathrm{M} 0.108 \pm 0.006$ \& ALN $0.2 \mu \mathrm{M} 0.118 \pm 0.003, \mathrm{p}=0.0044 \&$ $p=0.0005$ ) (Fig. 7). This positive effect that ALN has on mineralisation was found to be dose dependent as the therapeutic dose increased the amount of calcium deposition by $45 \%$ compared to $33 \%$ with the half dose. In comparison, ZA at both doses had no significant effect on mineralisation. 


\section{DISCUSSION}

Dental implant therapy in BP-medicated patients could have two possible negative outcomes; implant loss due to failure in osseointegration and BRONJ within the implant surgical site. At present, there are mixed findings in the literature regarding the risk of these outcomes in BP patients. A recent systematic review by Mendes et al. ${ }^{13}$ clearly delineated the variation in findings with a history of BP therapy with some studies reporting slightly lower survival rates and higher incidences of BRONJ, while other studies reported no remarkable differences in patients with a history of BP therapy when compared to healthy patients. Furthermore, a review of animal studies by Vohra et al. ${ }^{14}$ noted most of the studies demonstrated that BPs enhanced osseointegration under osteoporotic conditions, wherein increased bone volume and bone-implant contact were observed in animals receiving systemic BP doses, compared to control animals. ${ }^{14}$ Given the variation in the clinical observations and animal experiments, further basic research into the possible mechanisms and pathways involved is warranted. To date, to the best of our knowledge, there has only been one other similar study that investigated the role of BPs on the osteogenesis during osseointegration. ${ }^{10}$ However, in their study concentrations of BPs equivalent to $1 / 1000^{\text {th }}$ of therapeutic doses were used and comparisons between the effects of other BPs, such as the widely used, highly potent ZA was not included. Therefore, the present study aimed to investigating the effects of therapeutic doses of ALN and ZA on the viability, proliferation, adhesion, and differentiation of osteoprogenitor cells cultured on titanium surfaces. 
In our study, cell viability appeared to be unaffected by therapeutic doses of ALN, but negatively affected by therapeutic doses of ZA. The negative effect of ZA at therapeutic doses could be attributed to its potency, as ZA is the most potent BP, approximately 20 times more potent than ALN. ${ }^{7}$ Furthermore, BRONJ is mainly observed in patients treated with ZA (intravenous), and less commonly with orally administered ALN (lower potency). ${ }^{8}$ Therefore, the fact that cell viability seemed to be adversely affected by therapeutic doses of ZA could provide some insight into the pathogenesis of BRONJ developing following implant placement in patients treated with ZA as there would be a reduction in viable cells to form new bone during the healing process. Previously, Huang et al. and Thibaut et al. reported a significant cytotoxic effect on MC3T3-E1 cells and human foetal osteoblasts (hFOBs) with concentrations of ZA higher than $10 \mu \mathrm{M} \cdot{ }^{15,16}$ This may suggest that the negative effect of ZA on cell viability is only significant at concentrations higher than the therapeutic dose. The in vivo study by Pozzi et al. supports this notion where it was shown that therapeutic doses of ZA decreased the numbers of osteoblasts per bone perimeter in mice without any statistical significance being reached. ${ }^{17}$ On the other hand, Pan et al., reported that ZA induced cell death in human adult OB-like cells at concentrations of $0.5 \mu \mathrm{M}$ or greater, in a dose dependent manner. ${ }^{18}$ Taken together with the existing literature, our results may suggest that cell viability in the context of osseointegration could be negatively affected by therapeutic doses of ZA.

Cell proliferation was initially inhibited by therapeutic doses of ALN and ZA, probably due to the initial shock of drug exposure, but then cells recovered with no overall long-term effects. In fact, Alqhtani et al., reported that lower doses of ALN (10 nM and $100 \mathrm{nM}$ ) significantly 
stimulated the proliferation of human mesenchymal stem cell (hMSCs) cultured on titanium surfaces. ${ }^{10}$ Similarly, Im et al. and Xiong et al. found that ALN significantly increased cell numbers over the controls in primary human trabecular bone cell culture and the MG-63 osteoblast-like cell line respectively, with the greatest effect at $10 \mathrm{nM} \cdot{ }^{19,20}$ Low concentrations of ZA also appear to induce proliferation of hMSCs as von Knoch et al. reported an increase in the number of cells that were treated with $10 \mathrm{nM}$ of ZA. ${ }^{21}$ On the other hand, a significant anti-proliferative effect on human term placental mesenchymal stem cells (pMSCs) was found in Sharma et al. with concentrations of ALN and ZA higher than $2 \mu \mathrm{M}$ and $1 \mu \mathrm{M}$ respectively. ${ }^{9}$ Orriss et al. also reported a significant inhibition of primary rat osteoblast cell growth and function with ZA at concentrations beyond $1 \mu \mathrm{M} .^{22}$ The findings of the present study may suggest that at therapeutic doses, ALN and ZA do not affect the proliferation of osteoprogenitor cells during osseointegration, however given the findings available in the literature, it is plausible that lower doses may enhance proliferation while higher doses may induce cytostasis.

Cell adhesion to the titanium disc was assessed by analysing the expression of F-actin, a cytoskeletal protein believed to be involved in regulating cellular shape change and force generation in activities such as migration, attachment and division. ${ }^{23}$ Firm adherence of osteoprogenitor cells is an important factor for cell survival and differentiation into osteoblasts, which over time become mature and produce fibronectin, an extracellular glycoprotein that regulates the adhesion, differentiation and function of various adherent cells. ${ }^{24}$ Our data showed that the amount of F-actin expression per viable cell remained unaffected by the addition of therapeutic doses of ALN and ZA to the culture media. This may 
suggest that as with cell proliferation, cell adhesion to the titanium implant surface is not affected by therapeutic doses of ALN and ZA.

Cell differentiation and subsequent osteogenesis, as measured by mineralisation, was stimulated by therapeutic doses of ALN. The ability of ALN to increase mineralisation was not surprising as previous in vivo studies have demonstrated that local drug delivery of BPs by way of implant coatings improves the fixation of titanium implants in human bone and increases peri-implant bone density in osteoporotic sheep. ${ }^{25,26}$ Furthermore, several in vitro studies have shown that ALN can affect osteoblastogenesis depending on its concentration, with a stimulatory effect observed at lower doses and an inhibitory effect at higher doses. ${ }^{6}$ Our results are in agreement with those reported by Alqhtani et al., ${ }^{10}$ suggesting that the anabolic effect of ALN on osteoblasts (in osseointegration) is maintained at therapeutic doses. Kim et al. found that the osteogenic differentiation of multipotent mouse mesenchymal stem cells was also enhanced after treatment with ALN at concentrations higher than in the present study. ${ }^{27}$ This may suggest that the stimulatory effect on osteoblast bone formation during osseointegration is also present at stronger concentrations than the therapeutic dose. However, Idris et al. found that ALN inhibits bone nodule formation in mice osteoblast cells above 2-10 $\mu \mathrm{M}$, thereby demonstrating that a ceiling effect on osteoblast formation exists at concentrations approaching this range. ${ }^{28}$ Pan et al. reported that ZA enhanced mineralised matrix formation in human adult osteoblast-like cells at concentrations higher than $0.5 \mu \mathrm{M}$, with an inhibitory effect observed at concentrations exceeding $5 \mu \mathrm{M} .{ }^{18}$ This was contrary to our findings and may be due to a range of factors including different cell type type, duration of treatment and therefore cumulative dose of $Z A$, and the presence of a titanium disc in our 
study. Nevertheless, the findings of this study may suggest that therapeutic doses of ALN could enhance the mineralisation potential of osteoblasts to improve osseointegration and implant success, whereas the same could not be confirmed for the therapeutic doses of ZA.

Although the present study used a well-established model to study osseointegration in vitro, there are three major limitations worth noting. The first limitation is that it was not possible to select drug concentrations that exactly correlate to physiological conditions. This is because the extent of cellular exposure within the body, particularly of osteoblasts to BPs are yet to be ascertained. ${ }^{5}$ As previously mentioned, the concentrations of BPs used in this study were selected based on the concentrations found in patient blood plasma after a single intake of the drug at therapeutic doses. While the peak plasma levels are considered to be transitory, BPs are taken up quickly and at increased concentrations into the osseous tissues, with very small amounts released into peripheral circulation during turn-over (long half-life drugs). ${ }^{18}$ Therefore, it is possible that osteoblasts in the bone microenvironment are exposed to BPs at concentrations several times higher than the patient's peak plasma level. In fact, one report estimated that therapeutic doses of ALN could give rise to local concentrations as high as 1 $\mathrm{mM}$ in sites of active bone resorption. ${ }^{29}$ The second limitation is that a mouse cell line (MC3T3E1) was used. James Cook University kindly donated these cells to us as they have been using them for other similar studies. While these cells provide a good and reliable model to study osteoblast biology, they do not represent human tissue as accurately as primary human cells would. ${ }^{30}$ The third limitation is that statistical analysis could not be performed for the viability assay as there were too many cells present, making a reliable and reproducible quantification 
impossible. Similar experiments utilizing primary human osteoblasts along with a range of seeding densities could be performed to allow for quantification of the live and dead cells.

In conclusion, our study using therapeutic concentrations of ALN and ZA on osteoprogenitor cells cultured on titanium showed the positive effect that ALN had on mineralisation that could have promising implications towards improved wound healing and osseointegration around dental implants. In contrast, a possible negative effect on cell viability caused by therapeutic doses of ZA may infer a greater risk of implant loss in terms of reduced osseointegration and BRONJ in these patients. Currently, minimal in vivo studies exists that evaluate the effects of systemic BPs on bone healing around dental implants and the findings within the existing studies vary significantly. Therefore, further research investigating the effects of systemic BPs on bone healing around dental implants, with an emphasis on animal and human studies, is warranted. 


\section{References}

1. Fiorellini J, Wada K, Sarmiento HL, Klokkevold PR. Periimplant Anatomy, Biology, and Function. In: Newman MG, Takei HH, Klokkevold, PR, Carranza FA (eds). Newman and Carranza's Clinical Periodontology. Philadelphia: Elsevier, 2019: 732-741.

2. Politis C, Schoenaers J, Jacobs R, Agbaje JO. Wound healing problems in the mouth. Front Physiol 2016;7:507.

3. Luo J, Miller C, Sharma D. Effect of nonsteroidal anti-inflammatory drugs on the osteogenic activity of osteoprogenitor cells cultured on titanium surfaces. Int J Oral Maxillofac Implants 2019;34(4):828-834.

4. Stavropoulos A, Bertl K, Pietschmann P, Pandis N, Schiødt M, Klinge B. The effect of antiresorptive drugs on implant therapy: systematic review and meta-analysis. Clin Oral Implants Res 2018;29(18):54-92.

5. Reinholz GG, Getz B, Pederson L, Sanders ES, Subramaniam M, Ingle JN et al. Bisphosphonates directly regulate cell proliferation, differentiation, and gene expression in human osteoblasts. Cancer Res 2000;60:6001-6007.

6. Maruotti N, Corrado A, Neve A, Cantatore FP. Bisphosphonates: effects on osteoblast. Eur J Clin Pharmacol 2012;68(7):1013-1018. 
7. Sharma D, Hamlet S, Petcu E, Ivanovski S. The effect of bisphosphonates on the endothelial differentiation of mesenchymal stem cells. Sci Rep 2016;6:1-11.

8. Sharma D, Ivanovski S, Slevin M, Hamlet S, Pop TS, Brinzaniuc K et al. Bisphosphonaterelated osteonecrosis of jaw (BRONJ): diagnostic criteria and possible pathogenic mechanisms of an unexpected anti-angiogenic side effect. Vasc Cell 2013;5:1-8.

9. Ruggiero SL, Dodson TB, Fantasia J, Goodday R, Aghaloo T, Mehrotra B et al. American association of oral and maxillofacial surgeons position paper on medication-related osteonecrosis of the jaw--2014 update. J Oral Maxillofac Surg 2014;72(10):1938-1956.

10. Alqhtani NR, Logan NJ, Meghji S, Leeson R, Brett PM. Low dose effect of bisphosphonates on hMSCs osteogenic response to titanium surface in vitro. Bone Rep 2017;6:64-69.

11. Zhang Y, Chen X, Tang Y, Lu Y, Guo L, Zhong D. Bioequivalence of generic alendronate sodium tablets $(70 \mathrm{mg})$ to Fosamax ${ }^{\oplus}$ tablets $(70 \mathrm{mg}$ ) in fasting, healthy volunteers: a randomized, open-label, three-way, reference-replicated crossover study. Drug Des Devel Ther 2017;11: 2109-2119.

12. Li P, Zhao Z, Wang L, Jin X, Shen Y, Nan C et al. Minimally effective concentration of zoledronic acid to suppress osteoclasts in vitro. Exp Ther Med 2018;15(6):5330-5336.

13. Mendes V, Dos Santos GO, Calasans-Maia MD, Granjeiro JM, Moraschini V. Impact of bisphosphonate therapy on dental implant outcomes: An overview of systematic review evidence. Int J Oral Maxillofac Surg 2019;48(3):373-381.

14. Vohra F, Al-Rifaiy MQ, Almas K, Javed. Efficacy of systemic bisphosphonate delivery on osseointegration of implants under osteoporotic conditions: Lessons from animal studies. Arch Oral Biol 2014:59:912-920. 
15. Huang X, Huang S, Guo F, Xu F, Cheng P, Ye Y et al. Dose-dependent inhibitory effects of zoledronic acid on osteoblast viability and function in vitro. Mol Med Rep 2016;13(1):613-22.

16. Thibaut F, Watrin T, Meary F, Tricot S, Legros V, Pellen-Mussi P et al. Effects of zoledronic acid on osteoblasts in three-dimensional culture. J Med Dent Sci $2015 ; 10(1): 8-15$.

17. Pozzi S, Vallet S, Mukherjee S, Cirstea D, Vaghela N, Santo L et al. High-dose zoledronic acid impacts bone remodelling with effects on osteoblastic lineage and bone mechanical properties. Cancer Res 2009;15(18):5829-5839.

18. Pan B, To LB, Farrugia AN, Findlay DM, Green J, Gronthos S et al. The nitrogencontaining bisphosphonate zoledronic acid, increases mineralisation of human bonederived cells in vitro. Bone 2004;34(1):112-123.

19. Im G, Qureshi SA, Kenney J, Rubash HE, Shanbhag AS. Osteoblast proliferation and maturation by bisphosphonates. Biomaterials 2004;25:4105-4115.

20. Xiong $Y$, Yang HJ, Feng J, Shi ZL, Wu LD. Effects of alendronate on the proliferation and osteogenic differentiation of MG-63 cells. J Int Med Res 2009;37(2):407-416.

21. von Knoch F, Jaquiery C, Kowalsky M, Schaeren S, Alabre C, Martin I et al. Effects of bisphosphonates on proliferation and osteoblast differentiation of human bone marrow stromal cells. Biomaterials 2005;26(34):6941-6949.

22. Orriss IR, Key ML, Colston KW, Arnett TR. Inhibition of osteoblast function in vitro by aminobisphosphonates. J Cell Biochem 2009;106(1):109-118.

23. Stricker J, Falzone T, Gardel ML. Mechanics of the F-actin cytoskeleton. J Biomech 2010;43(1):9-14. 
24. Terheyden H, Lang NP, Bierbaum S, Stadlinger B. Osseointegration--communication of cells. Clin Oral Implants Res 2012;23:1127-1135.

25. Abtahi J, Tengvall P, Aspenberg PA. Bisphosphonate-coating improves the fixation of metal implants in human bone: A randomized trial of dental implants. Bone 2012;50(5):1148-1151.

26. Stadelmann VA, Gauthier O, Terrier A, Bouler JM, Pioletti DP. Implants delivering bisphosphonate locally increase periprosthetic bone density in an osteoporotic sheep model: A pilot study. Eur Cell Mater 2008;16:10-16.

27. Kim HK, Kim JH, Abbas AA, Yoon TR. Alendronate enhances osteogenic differentiation of bone marrow stromal cells: a preliminary study. Clin Orthop Relat Res 2009;467(12):3121-3128.

28. Idris Al, Rojas J, Greig IR, van't Hof RJ, Ralston SH. Aminobisphosphonates cause osteoblast apoptosis and inhibit bone nodule formation in vitro. Calcif Tissue Int 2008;82:191-201.

29. Sato M, Grasser W, Endo N, Akins R, Simmons H, Thompson DD et al. Bisphosphonate action. alendronate localization in rat bone and effects on osteoclast ultrastructure. J Clin Invest 1991;88:2095-2105.

30. Hwang PW, Horton JA. Variable osteogenic performance of MC3T3-E1 subclones impacts their utility as models of osteoblast biology. Sci Rep 2019;9(1):8299. 


\section{ACKOWLEDGEMENTS}

The authors wish to acknowledge the James Cook University College of Medicine and Dentistry Honours program and the Australian Dental Research Foundation Colin Cormie Grant for funding this study. 
COMPETING INTERESTS

The authors declare that there are no conflicts of interest. 


\section{FIGURE LEGENDS}

Figure 1. MC3T3-E1 cells viewed at $x 10$ (a) and x20 (b) magnification. Notes: Images were taken prior to passaging at $95 \%$ confluence. Sample size $=3$ replicates per group. Scale bar $=$ $100 \mathrm{px}$

Figure 2. Example of a titanium disc after sandblasting. Notes: The diameter of the titanium disc $(14 \mathrm{~mm})$ was designed to be less than the diameter of the well $(22.1 \mathrm{~mm})$ to facilitate manipulation of the disc during the imaging experiments.

Figure 3. Effect of ALN and ZA on MC3T3-E1 cell viability. These results demonstrated that cell viability was negatively affected by therapeutic doses of ZA after 10 days of treatment, while all other groups had no effect on cell viability at both time points. Notes: Images taken at x10 magnification after 3 days (a-e) and 10 days (f-j). Live cells stained green with CytoPainter. Dead cells stained red with Propidium lodide.

Figure 4. Effect of ALN and ZA on MC3T3-E1 cell proliferation. These results demonstrated that cell proliferation was initially significantly inhibited by both doses of ALN and the 
therapeutic dose of ZA, but then the cells recovered with no overall long-term effects, while half the therapeutic dose of ZA had no significant effect on cell proliferation. Notes: Significant differences, compared to control are indicated as $* \mathrm{p}<0.05$.

Figure 5. Effect of ALN and ZA on MC3T3-E1 cell adhesion. These results demonstrated that cell adhesion was not significantly affected by ALN and ZA at both the doses used. Notes: Scale bar $=200 \mu \mathrm{m}$ (a-e), $50 \mu \mathrm{m}(\mathrm{f}-\mathrm{j})$. Images taken at x10 (a-e) and x40 (f-j) magnification after 24-hours. F-actin cytoskeleton stained red with Flash Phalloidin ${ }^{\mathrm{TM}}$ Red. Cell nucleus stained blue with DAPI.

Figure 6. Quantitative analysis of cellular adhesion showing no statistically significant differences between ALN and ZA group at any of the tested doses.

Figure 7. Effect of ALN and ZA on MC3T3-E1 mineralisation. These results demonstrated that mineralisation was significantly enhanced by ALN in a dose dependent manner, while both doses of ZA had no significant effect on mineralisation. Notes: Significant differences, compared to control are indicated as $* * p<0.01, * * * p<0.001$ 


\section{TABLE LEGEND}

Table 1. Selected drugs and drug concentrations used in this study. Notes: *No treatment, ${ }^{11}$ Zhang et al., ${ }^{12}$ Li et al. 


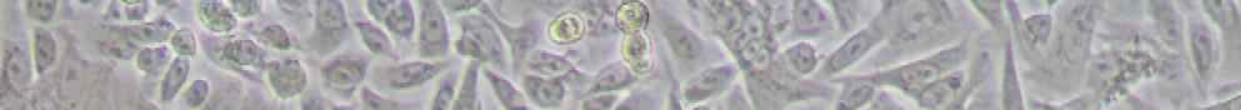

(1)

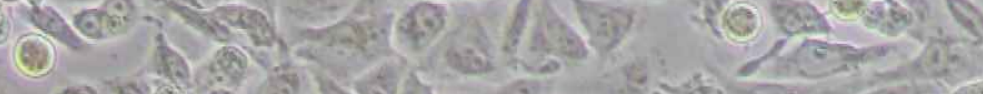

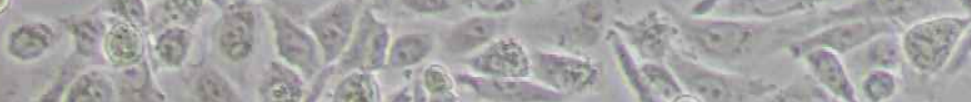

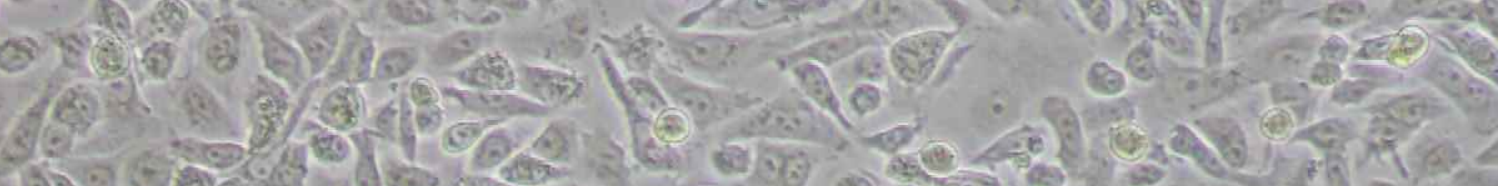
26 (3)

10.0 (4)

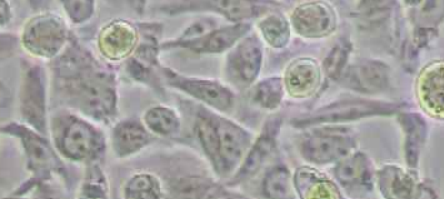

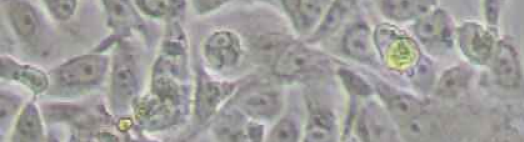

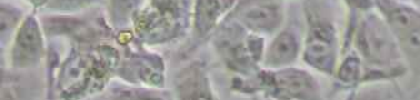

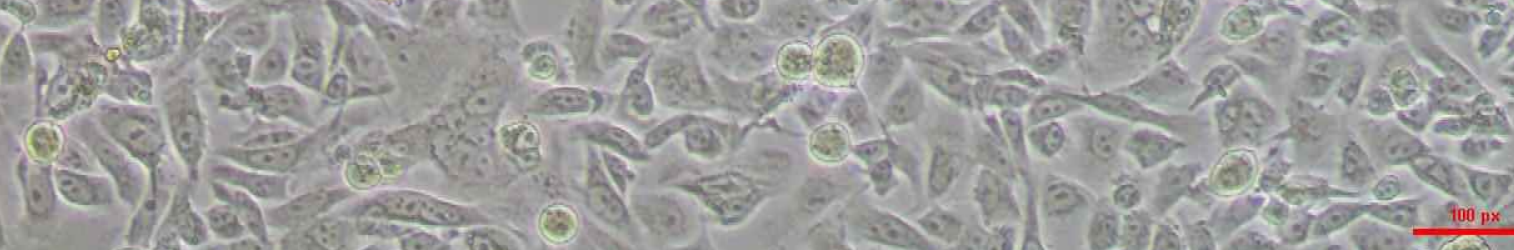
10.

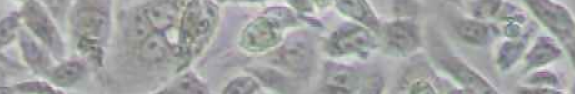

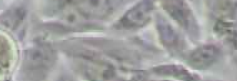

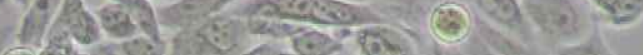



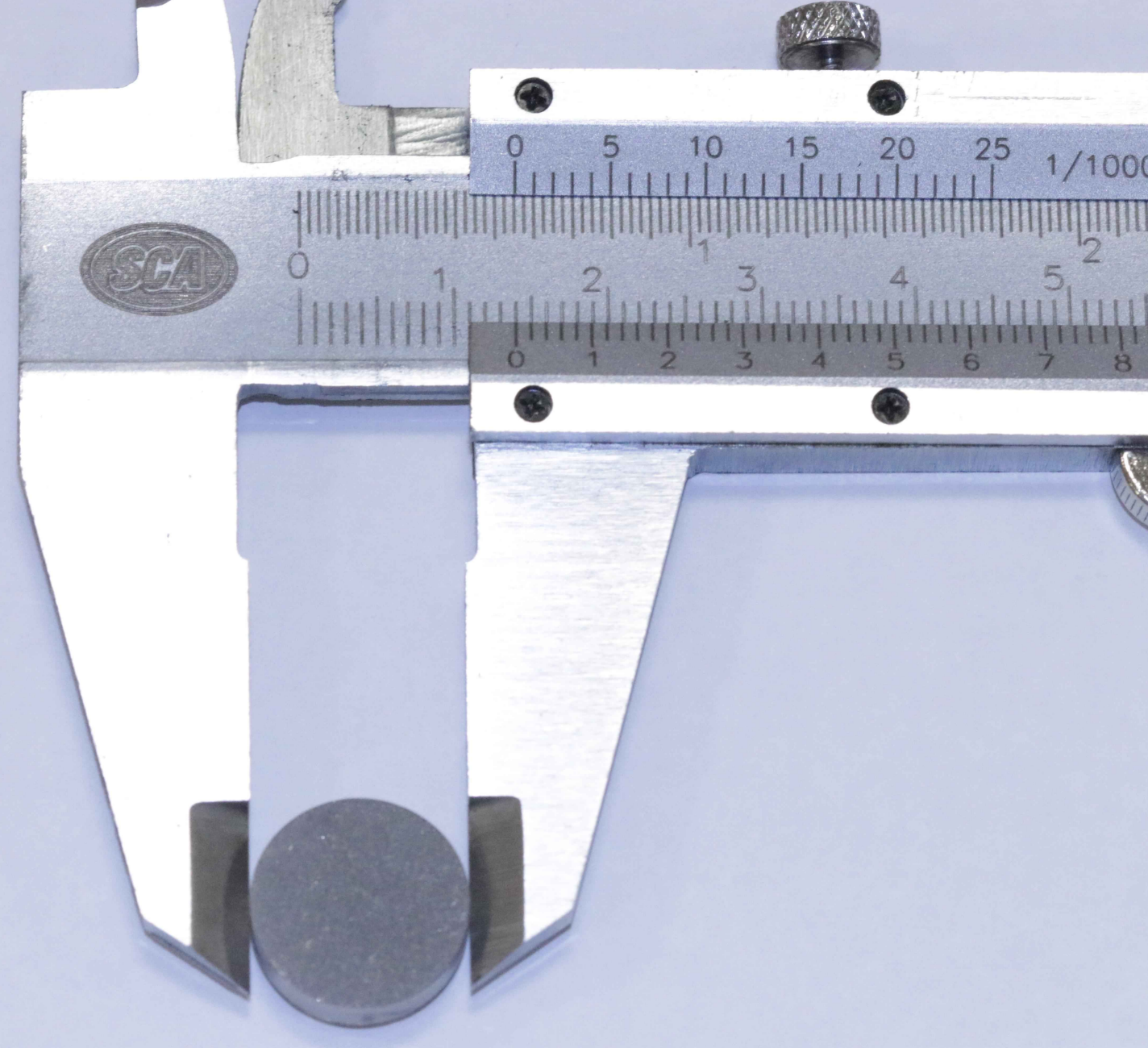


\section{Control}




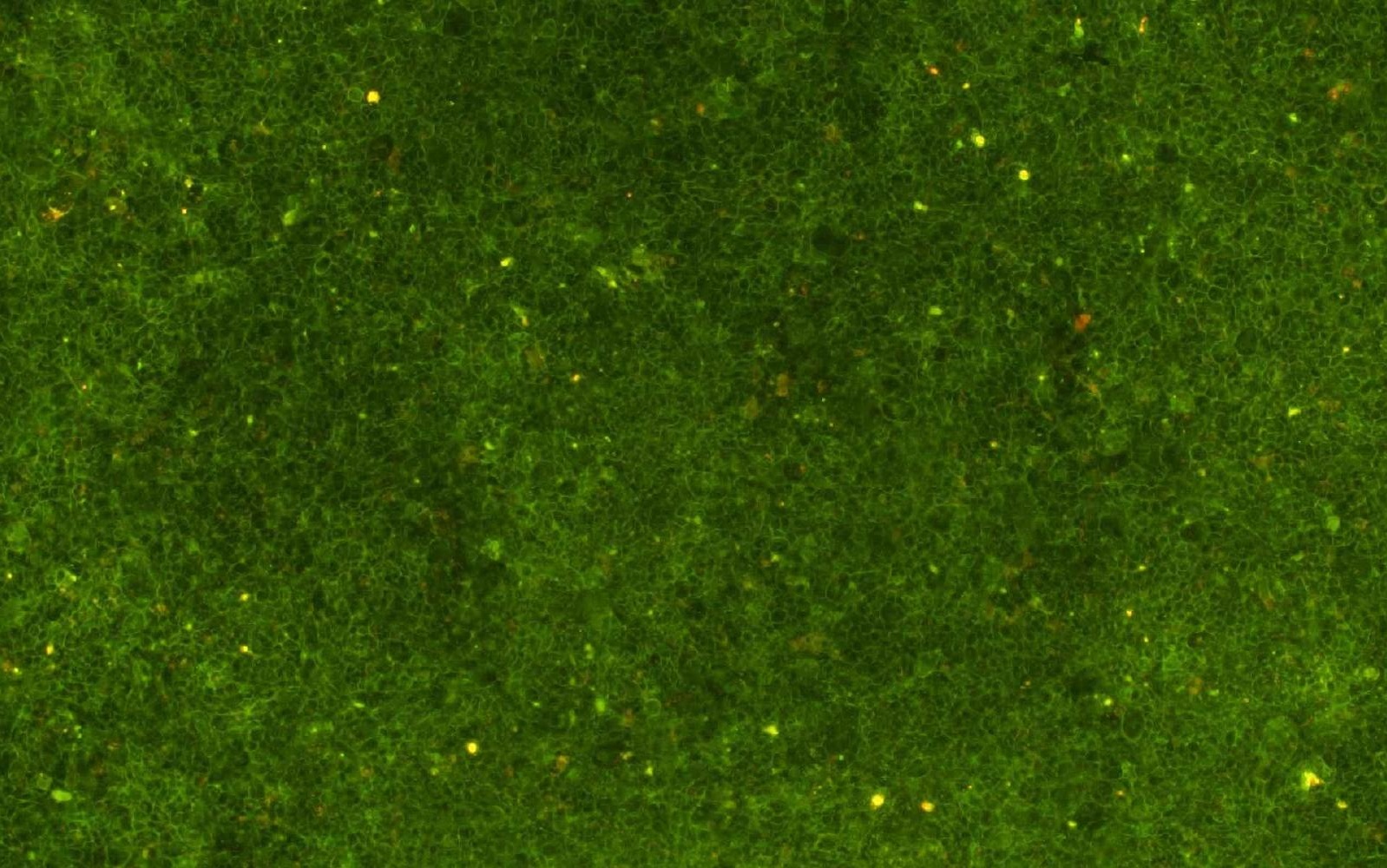


ALN $0.1 \mu \mathrm{M}$

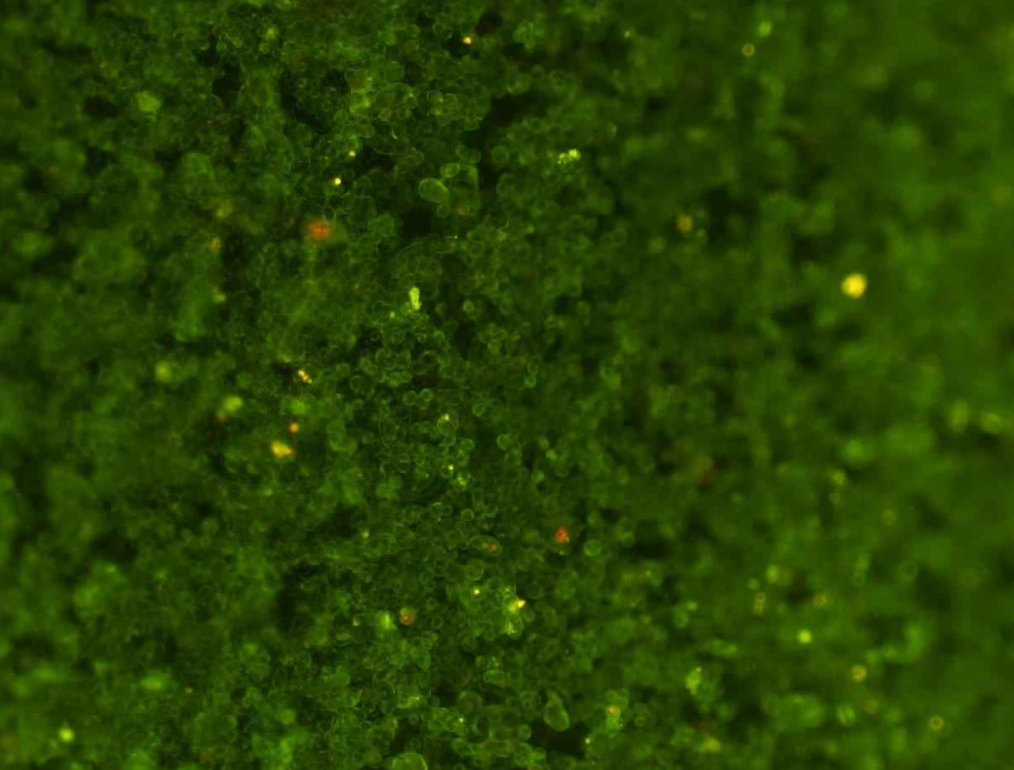

ats 


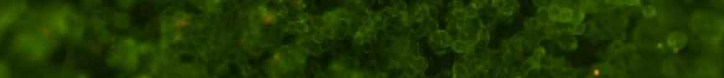

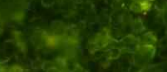

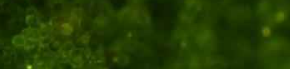

2

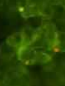

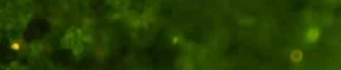

*

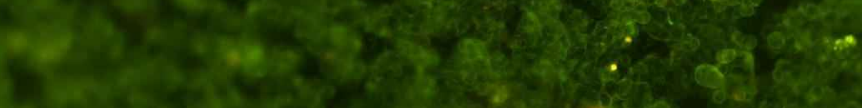

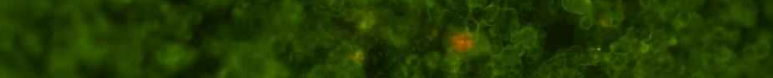

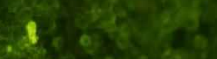

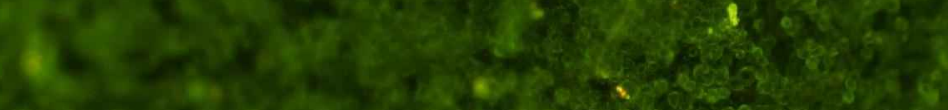

2.5.2.

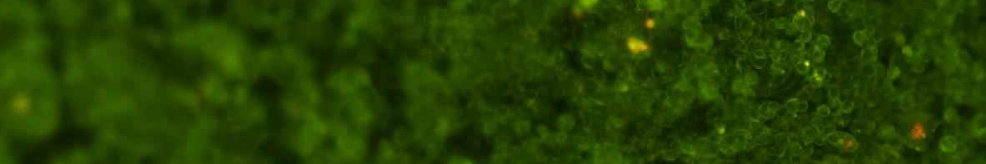

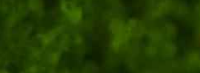

2.8.

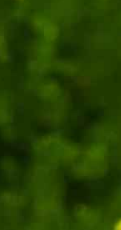

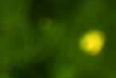

(3)
8

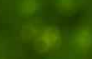

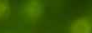
- 


\section{ALN $0.2 . \mu \mathrm{M}$}

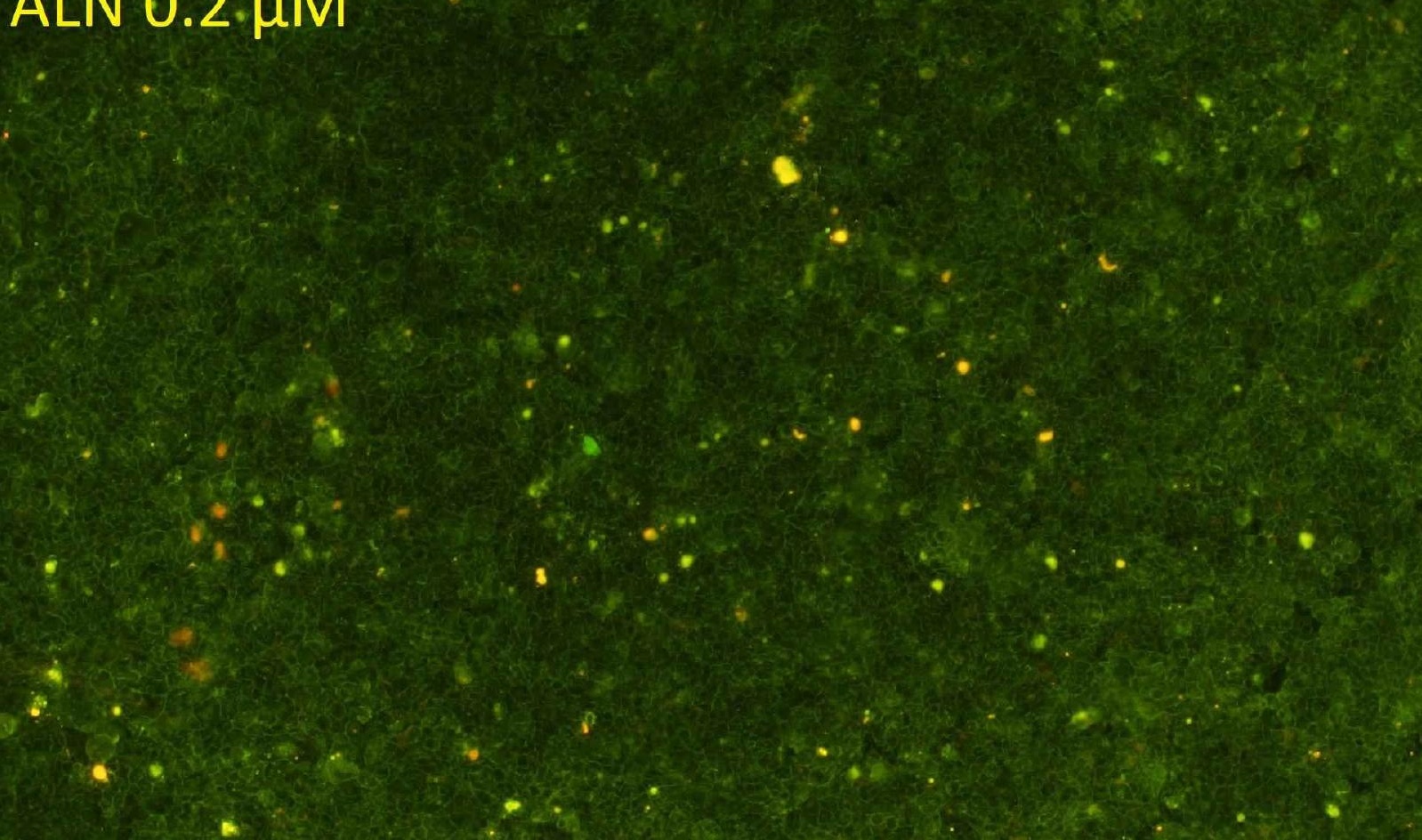

- 98

Natse

yetis

cis 
*

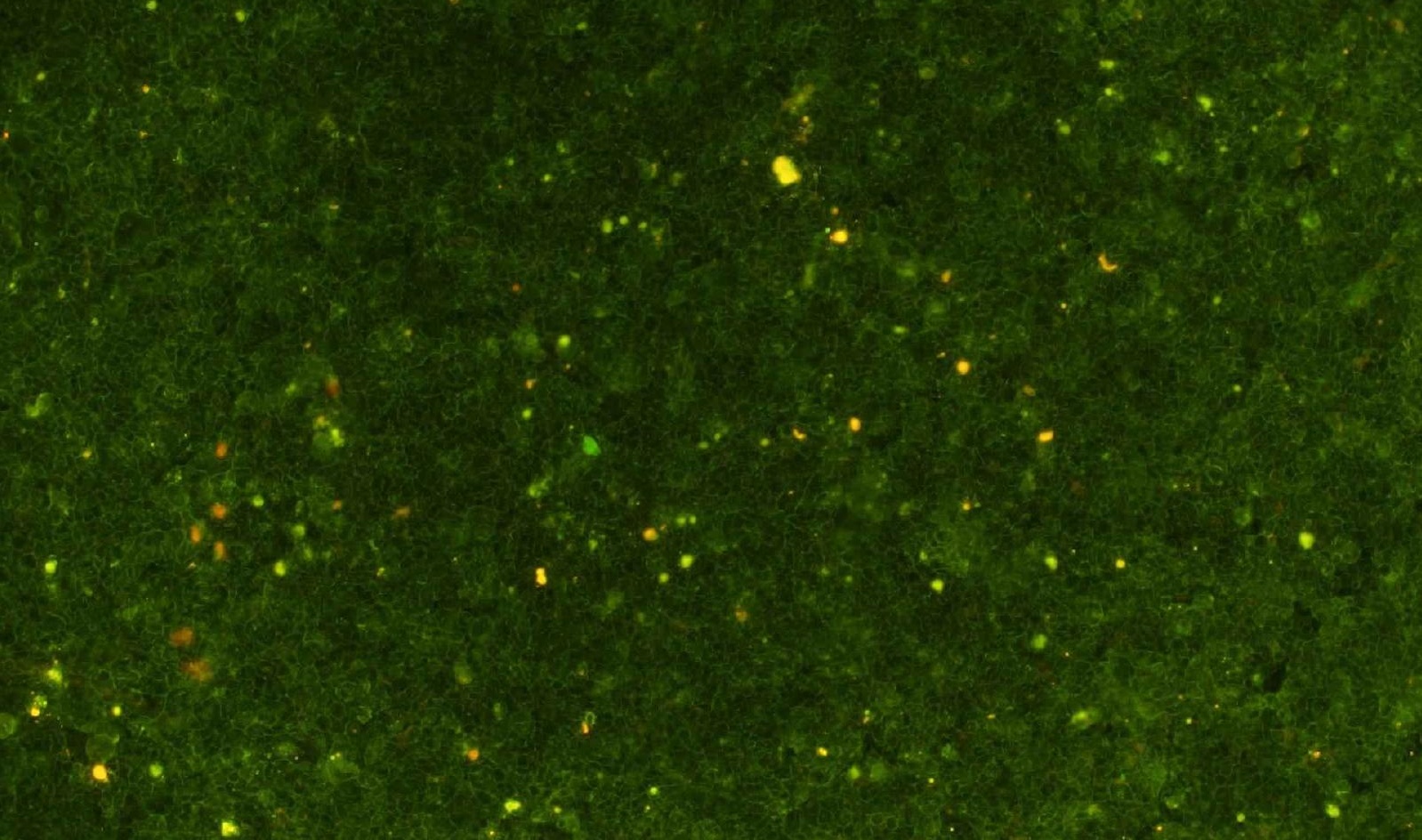




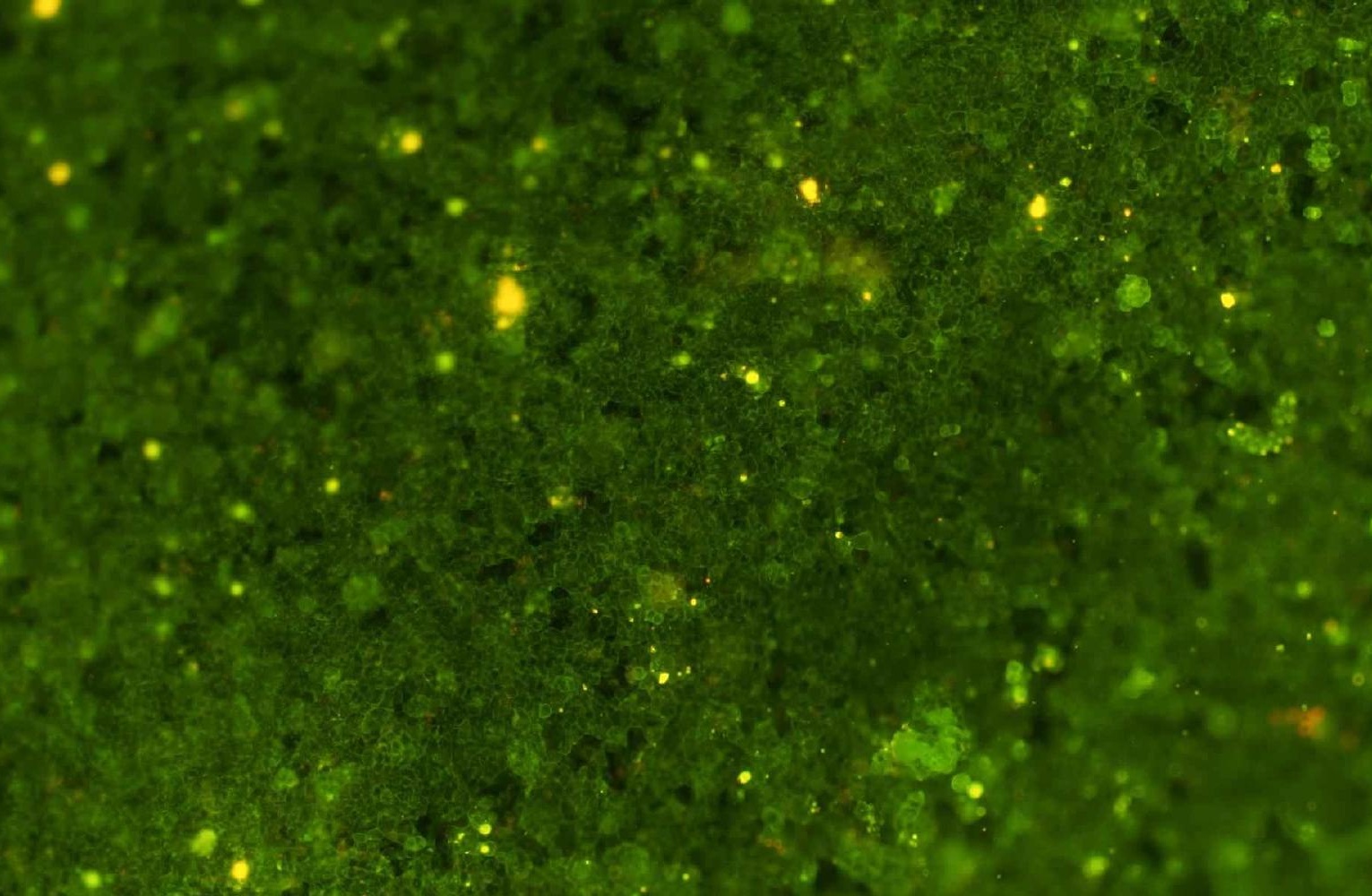




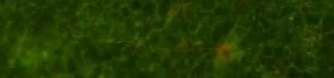

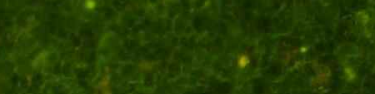

es

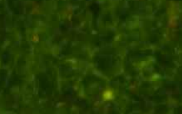

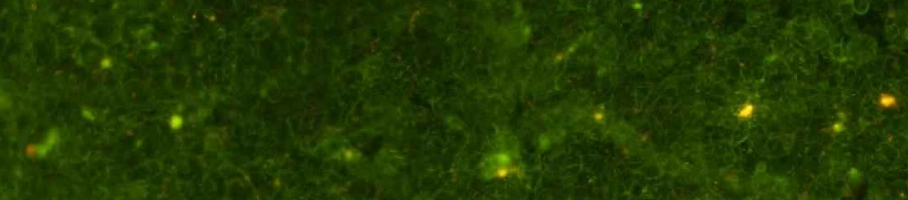

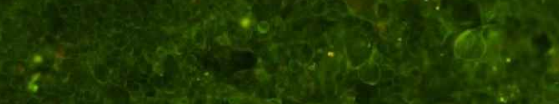

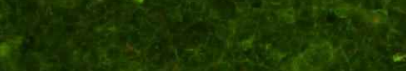

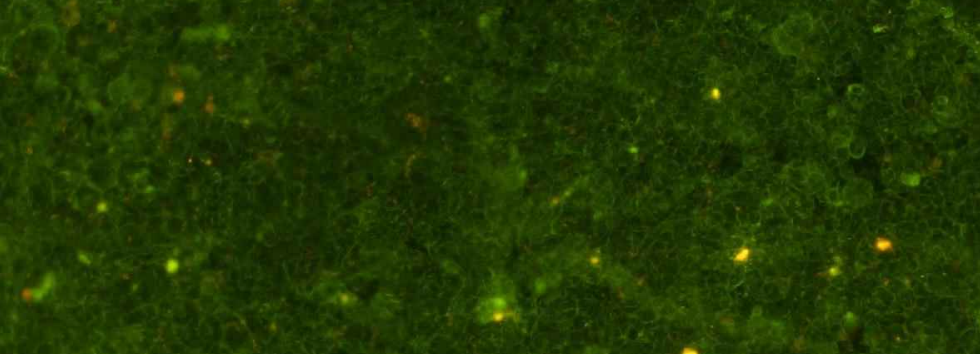

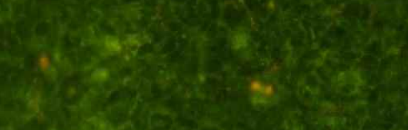

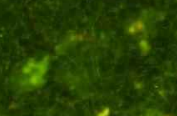

29

9

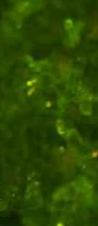

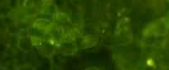

$\operatorname{lin}^{1}-\sin ^{2}$ (1) 58

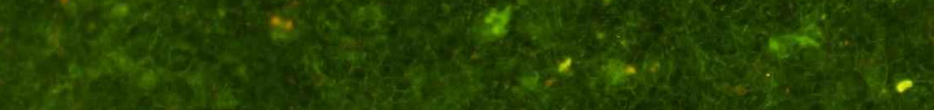

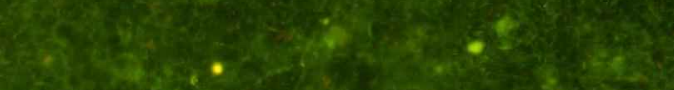

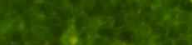

What inations

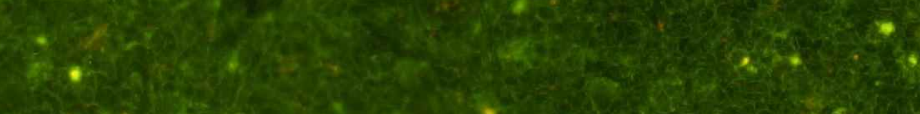

20.6?
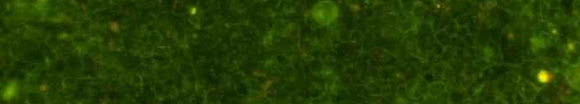

$\frac{1}{8}$

t.

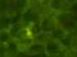

$\log ^{2}, 00$

axt. 


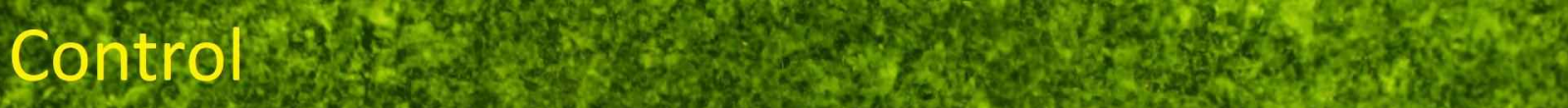

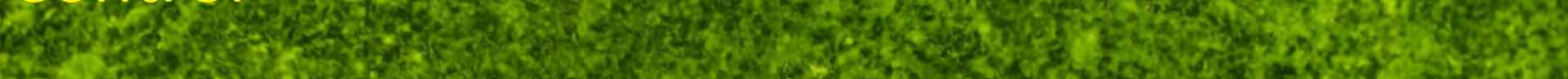
A.t. s. W.

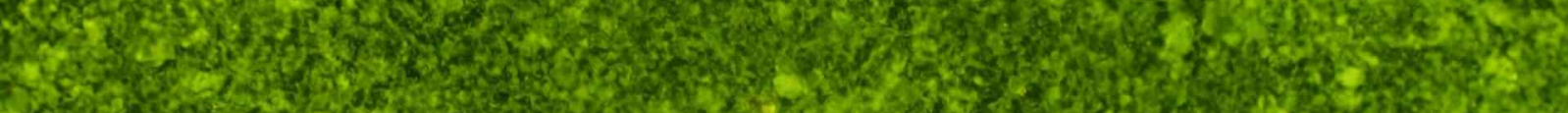

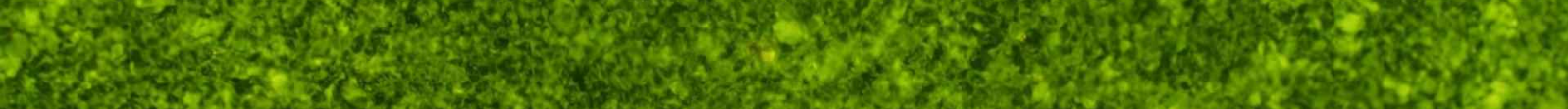

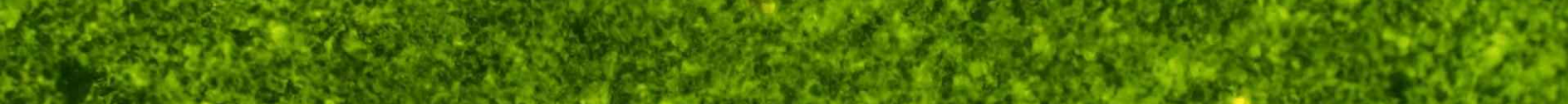

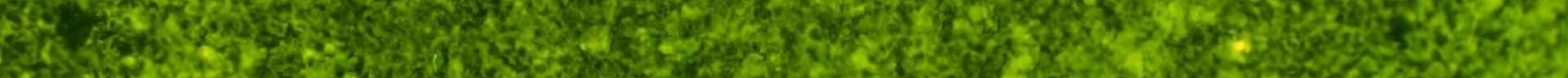

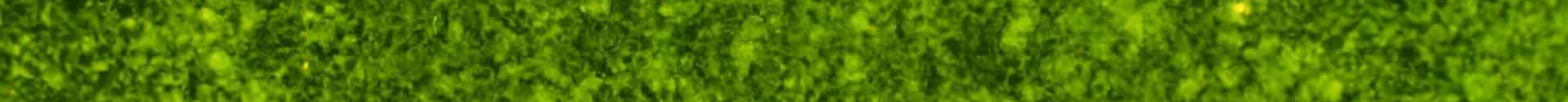

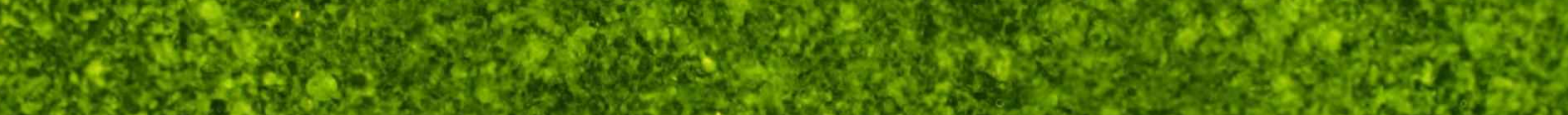

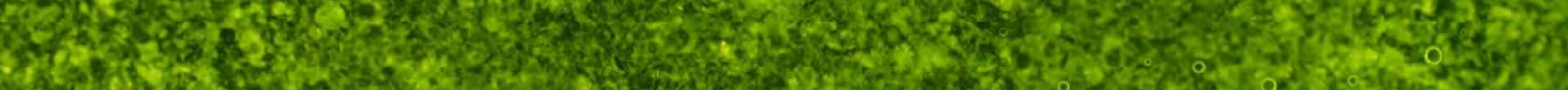
W.

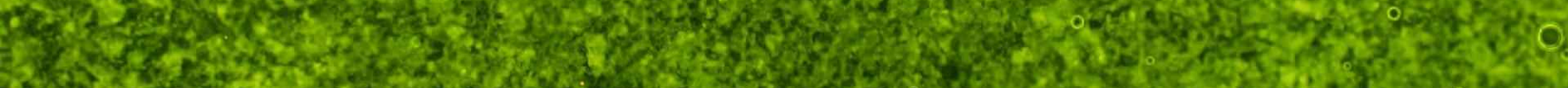

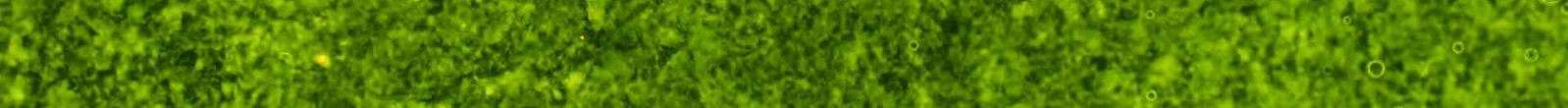
If Sf

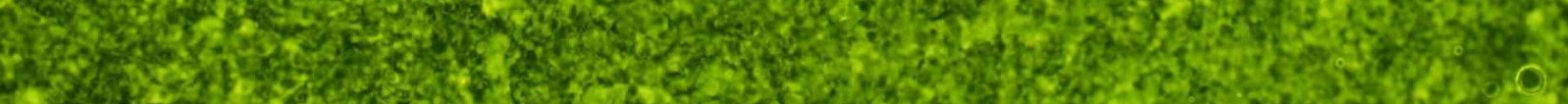




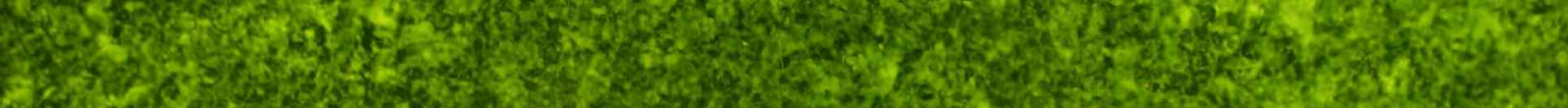

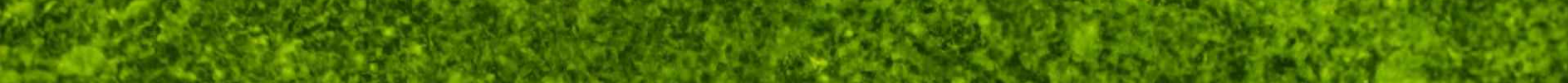
A.

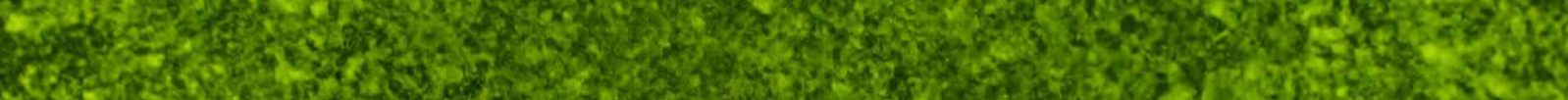

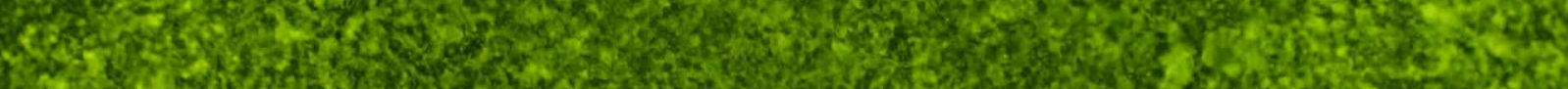

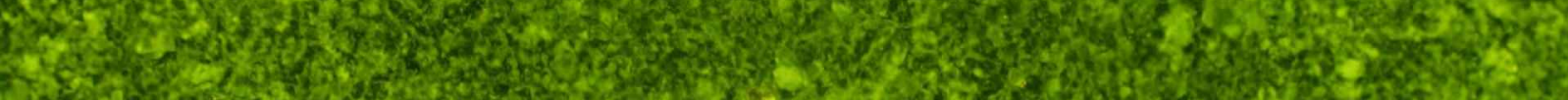
1.5. * W. - 50 .

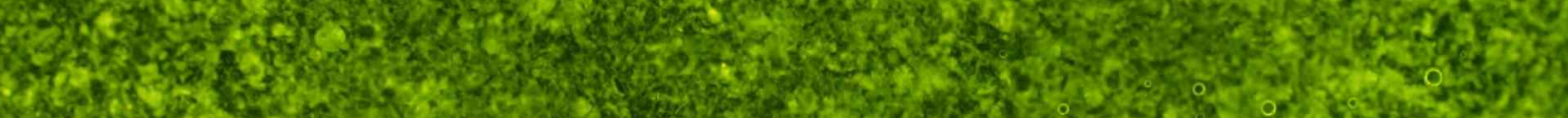

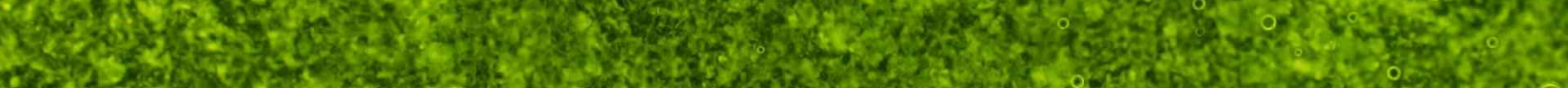

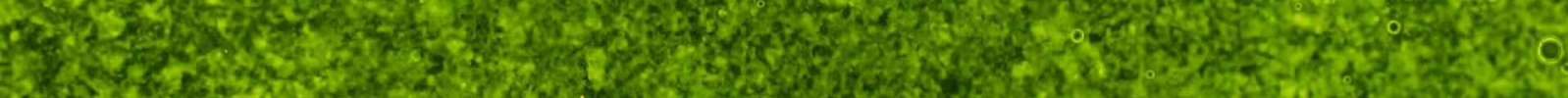

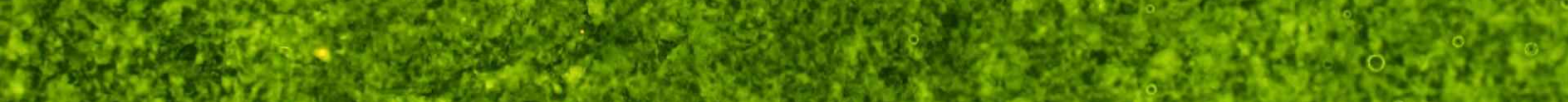

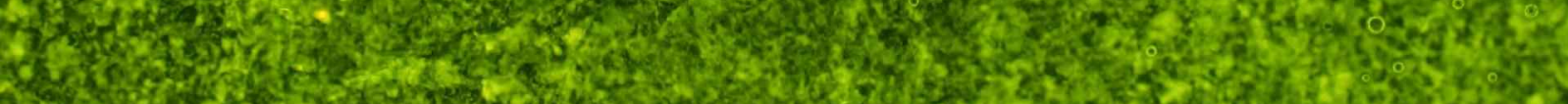

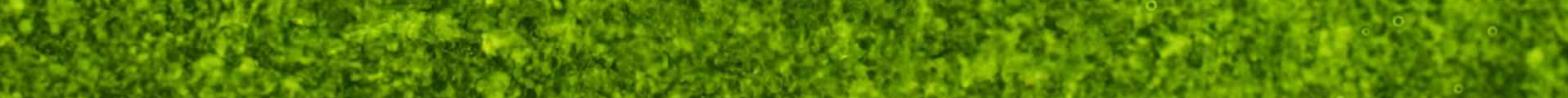

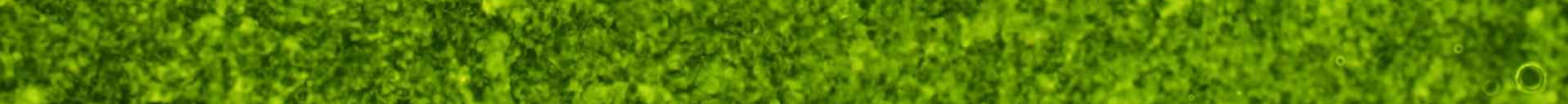




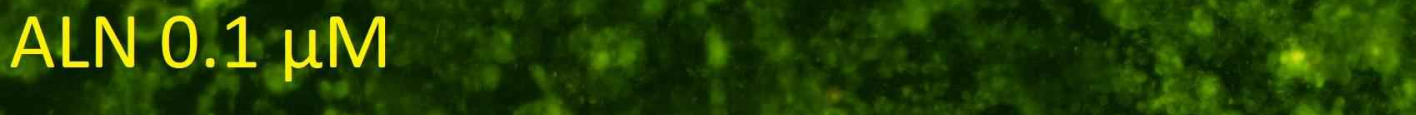

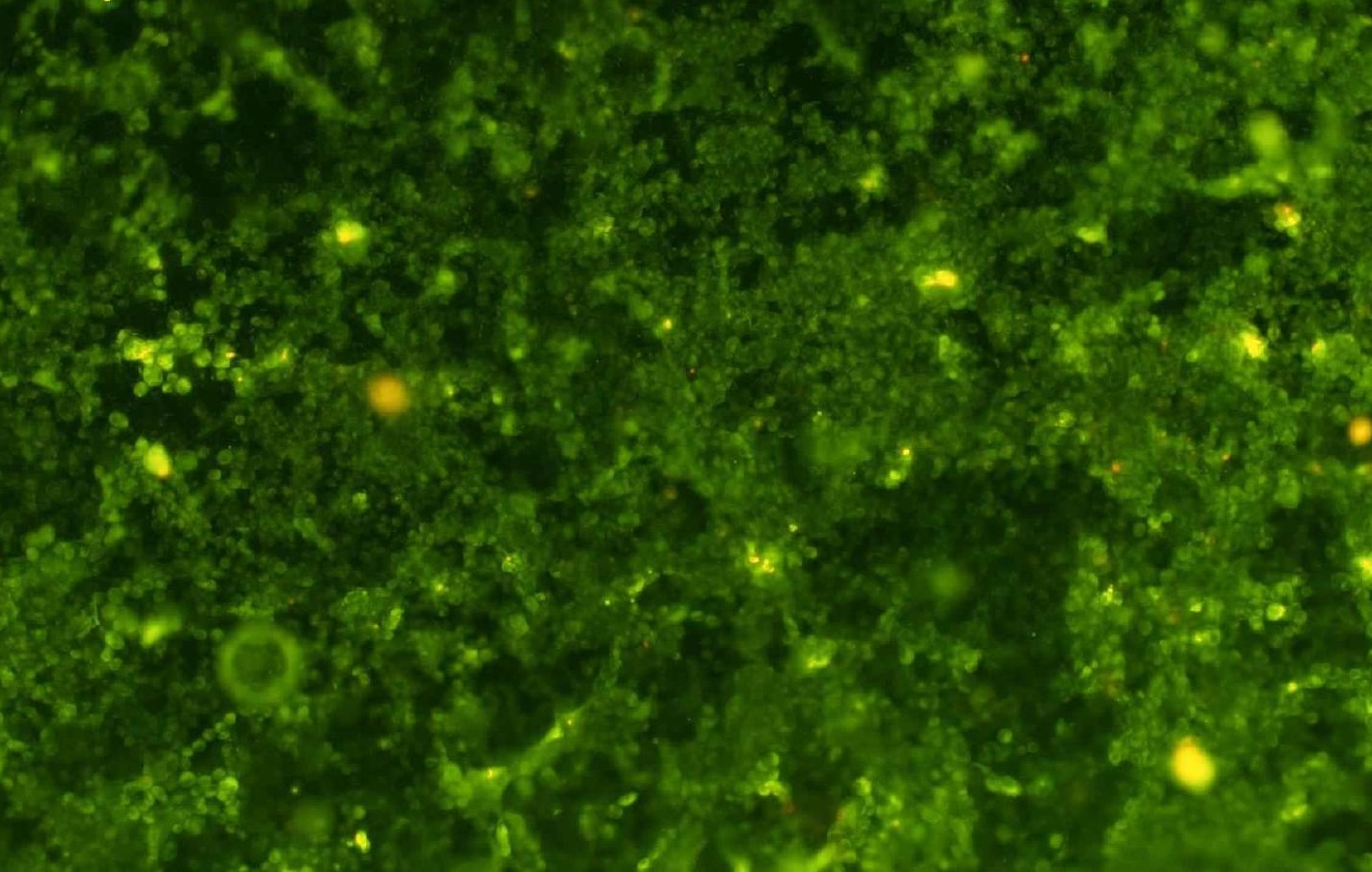




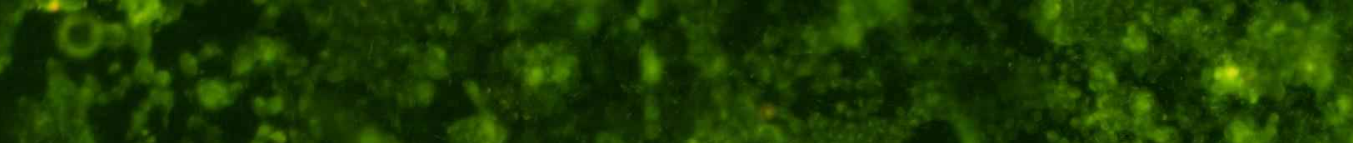

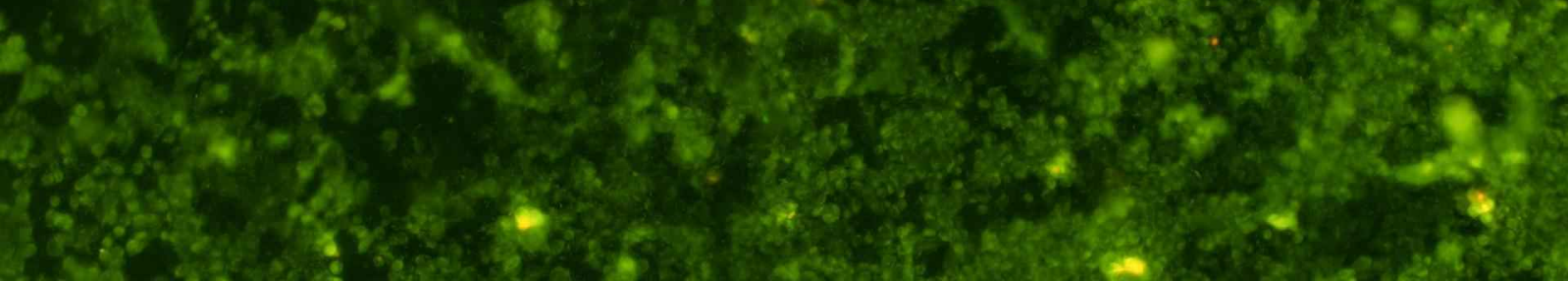

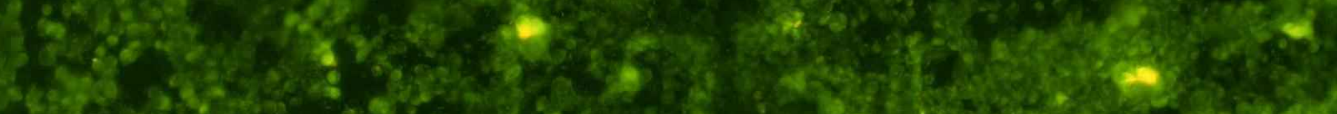

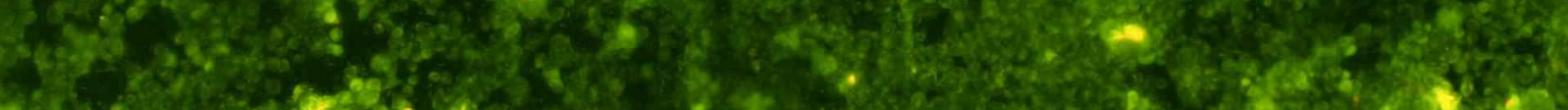

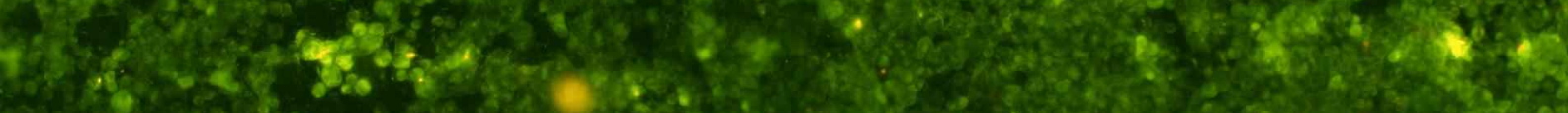

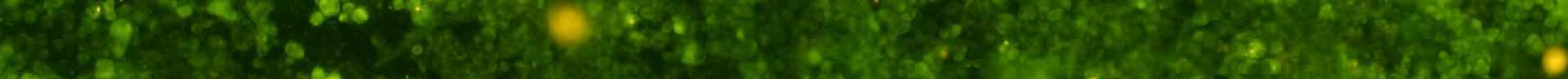

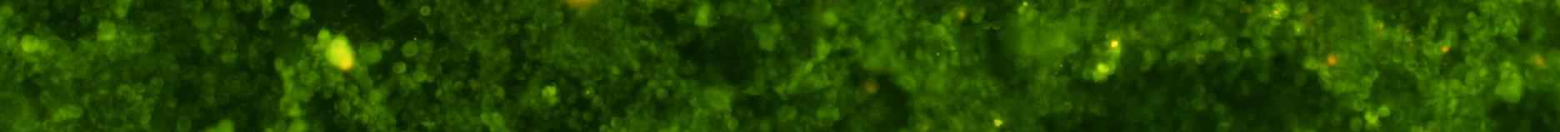

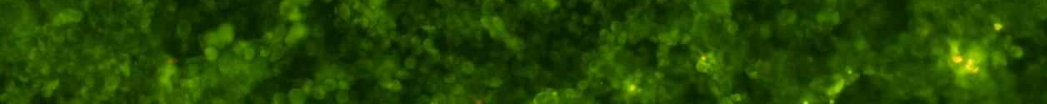

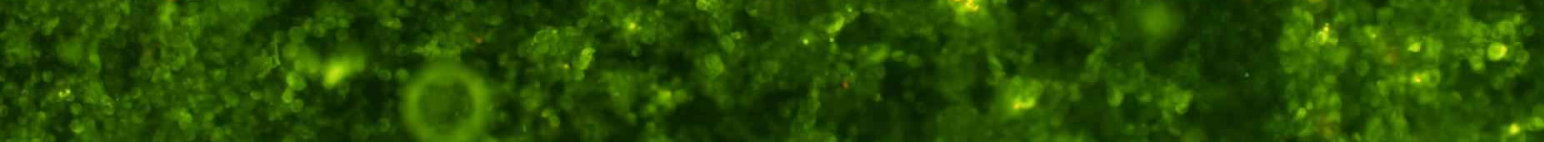

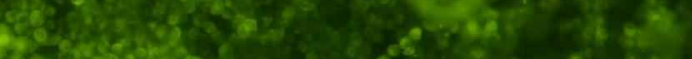

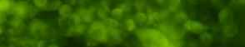

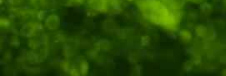

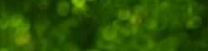

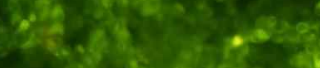
(4) (9) 
ALN $0.2 \mu \mathrm{M}$

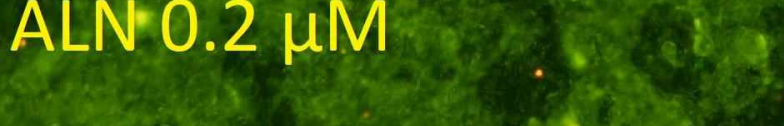

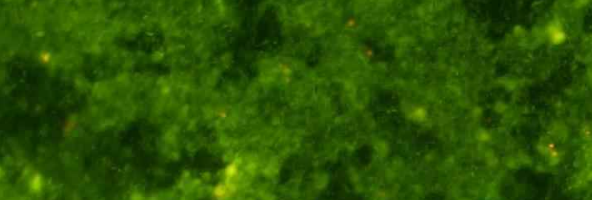

6.

6.

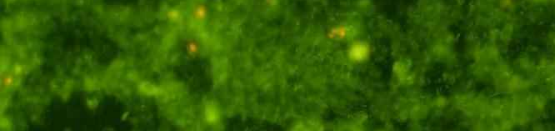

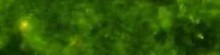
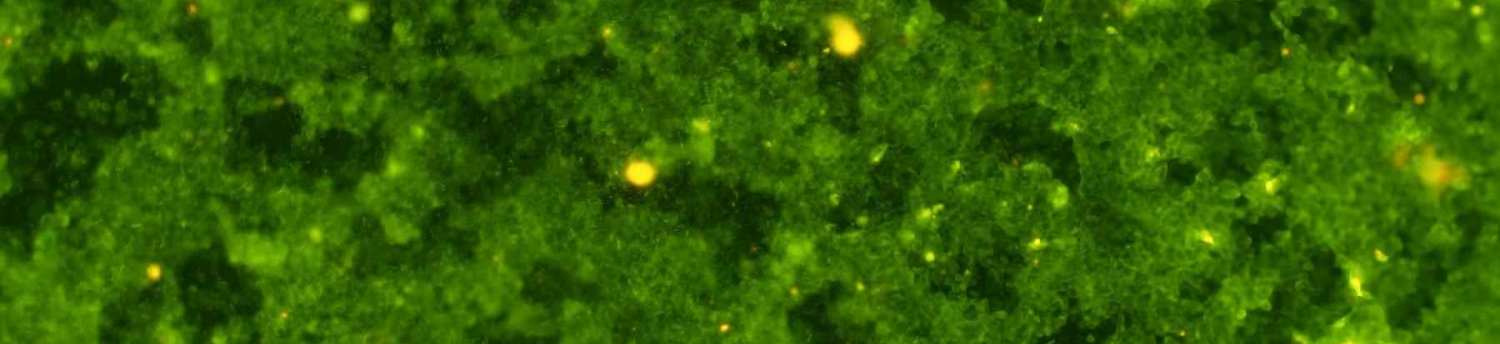

e.?

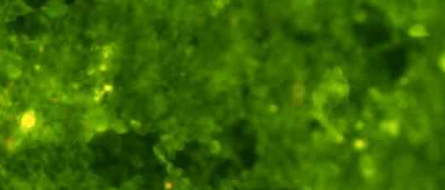

a. 


\section{*

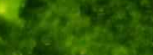




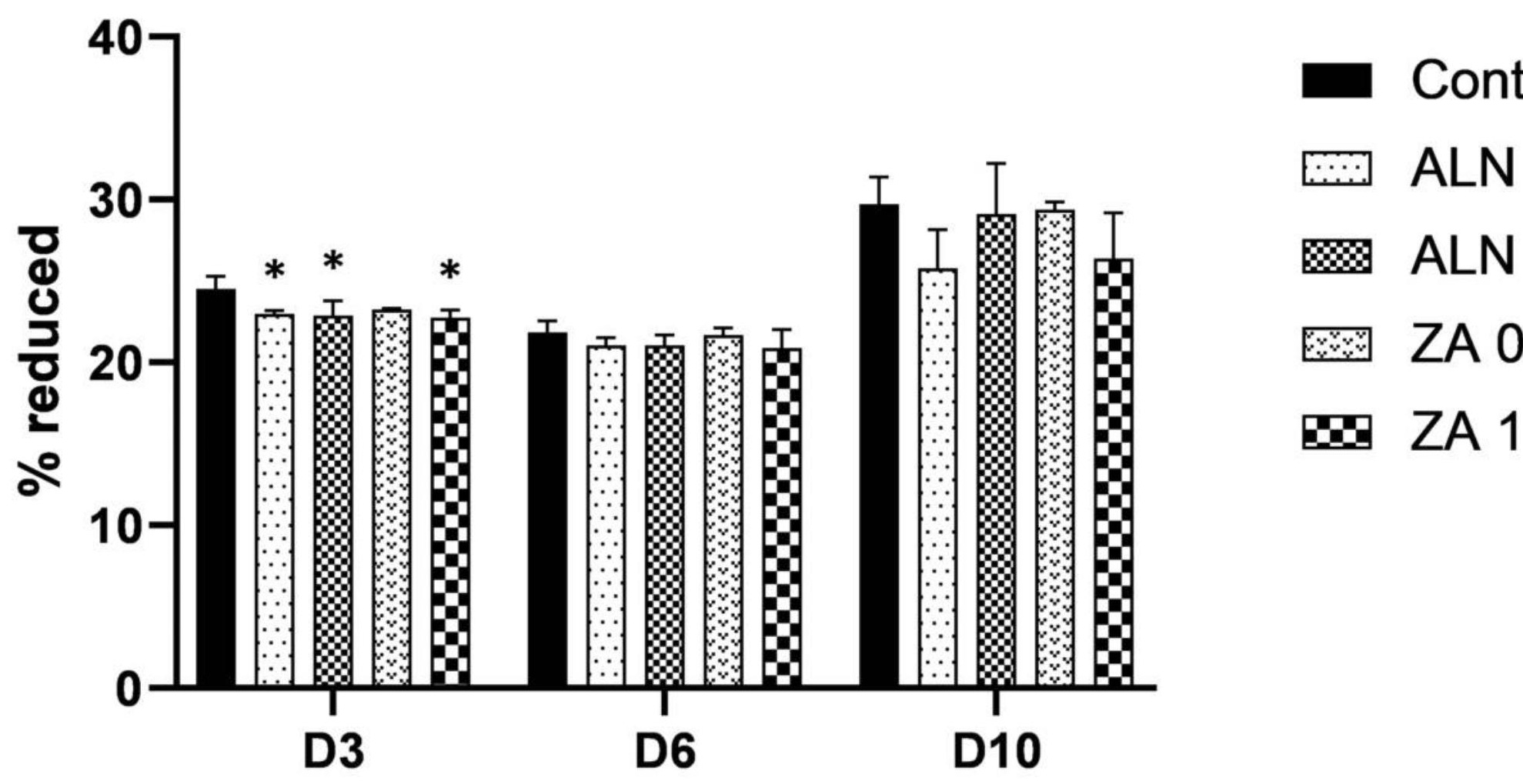




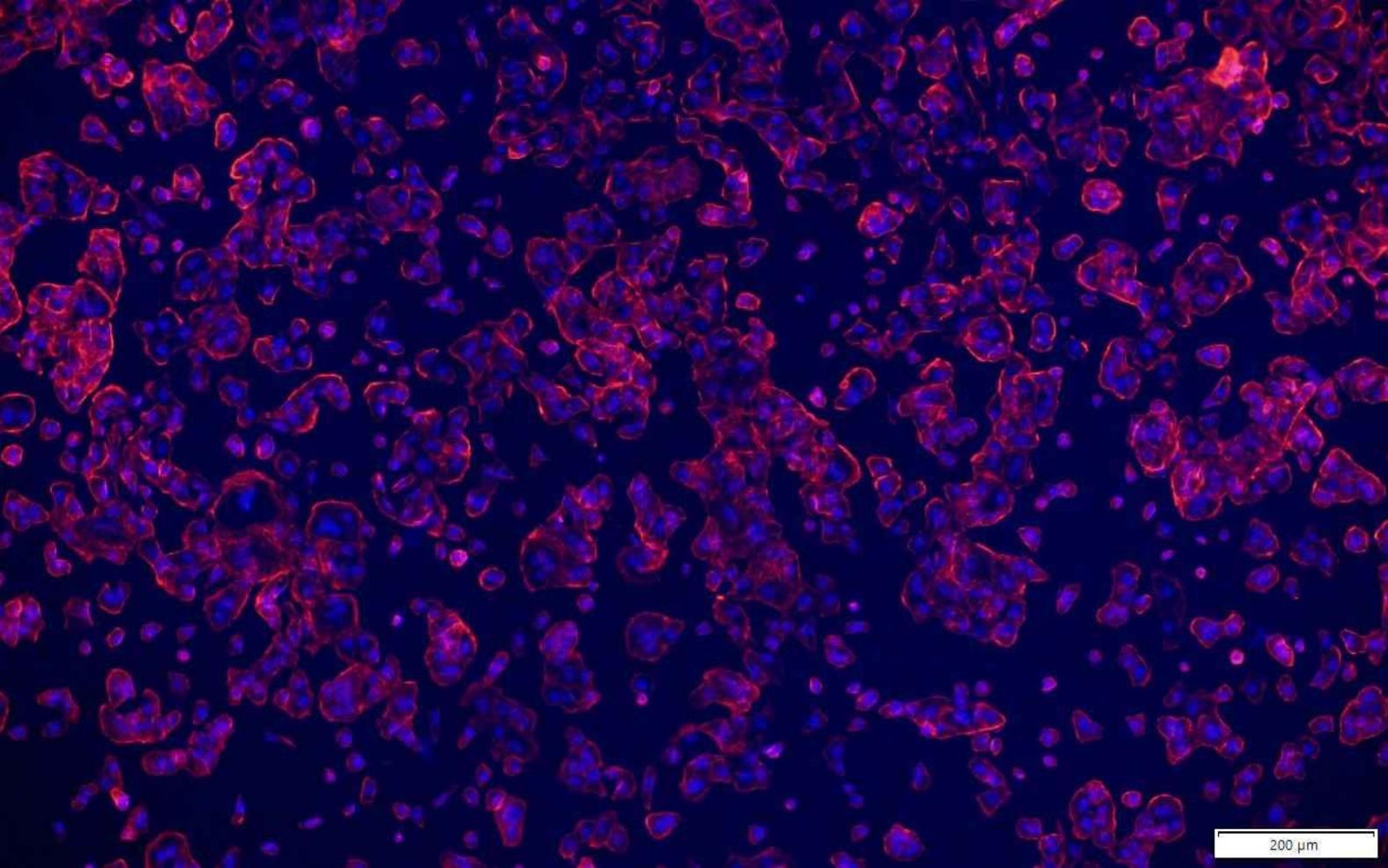


ALN $0.1 \mu \mathrm{M}$

a 6
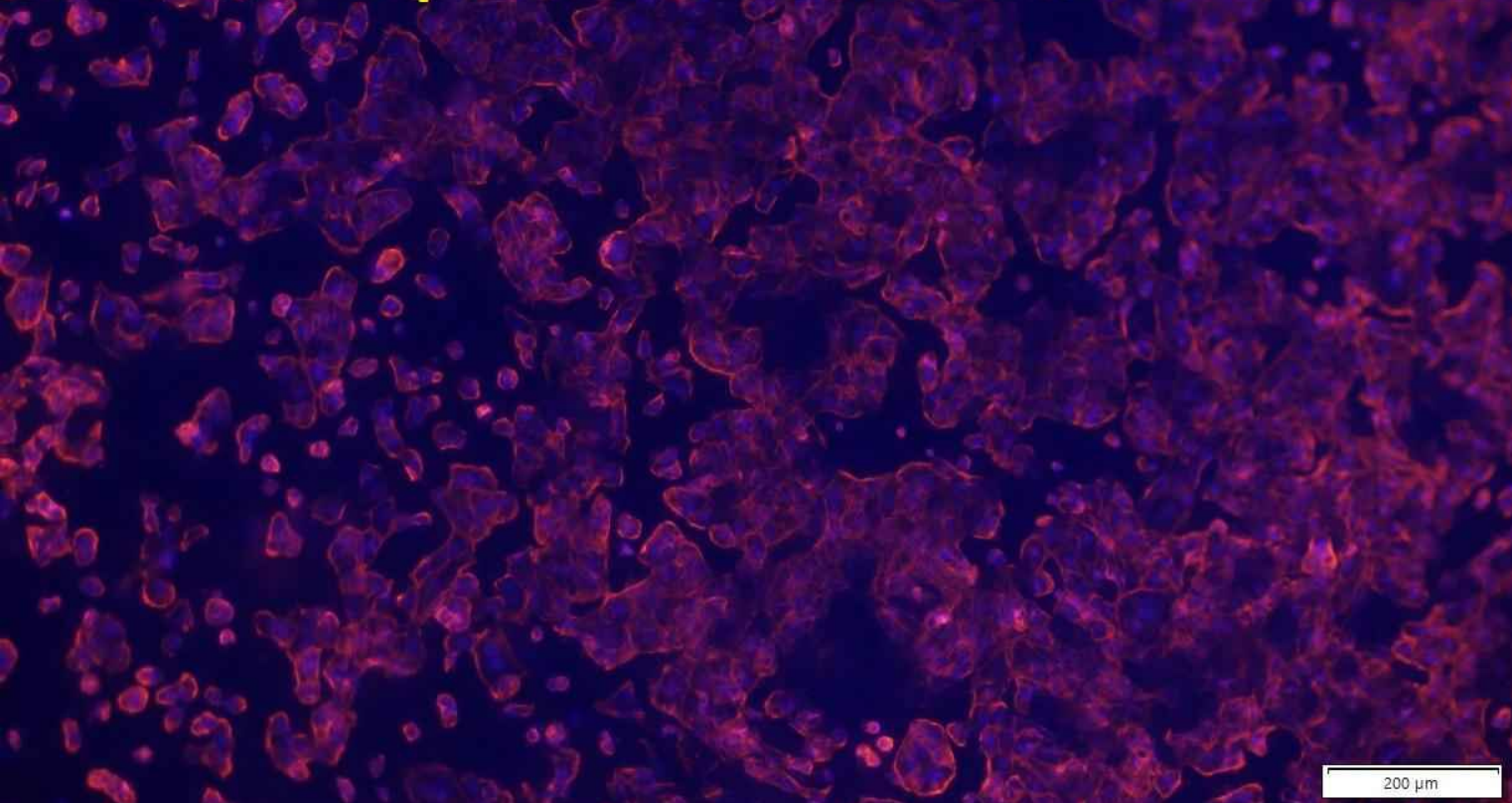


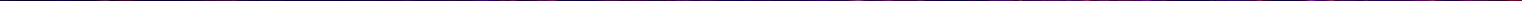




\section{$\mathrm{ZA} 0.5 \mu \mathrm{M}$}<smiles>C=C[As]=[W]</smiles>

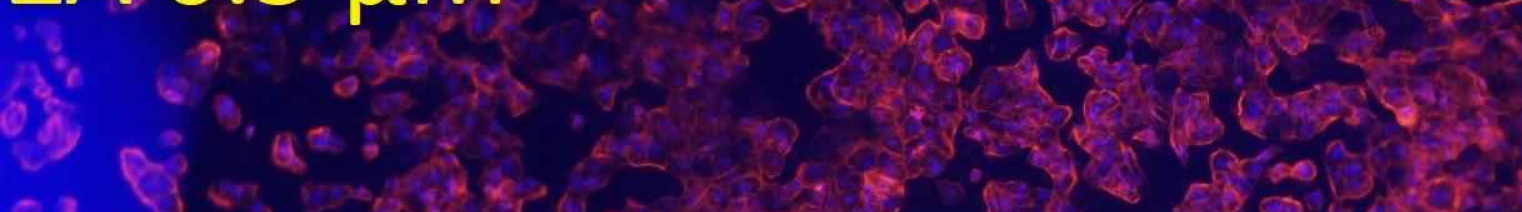

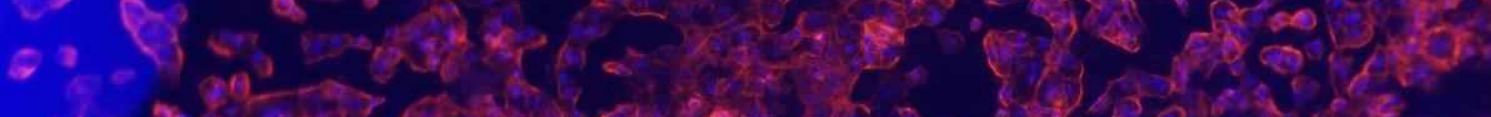

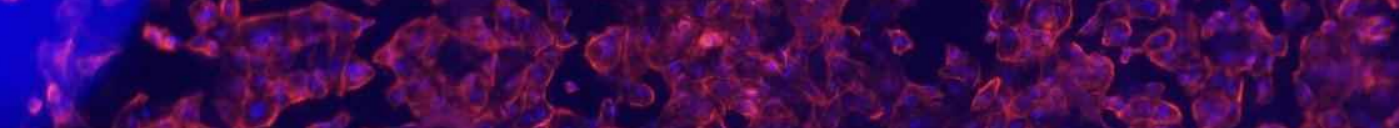
$\therefore$ स

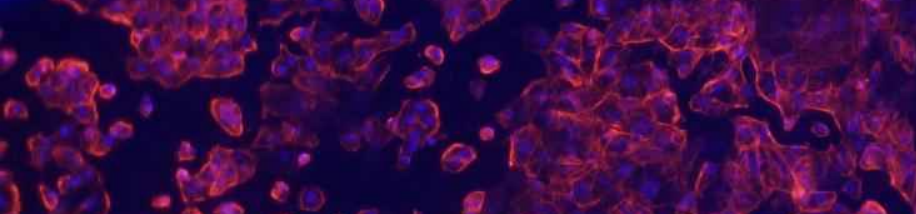

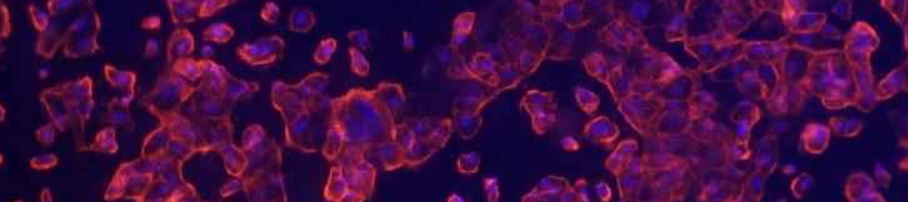
El $350 \mathrm{~s}$ 



\section{$\mathrm{ZA} 1 \mu \mathrm{M}$}

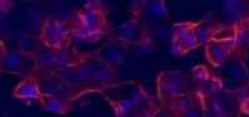

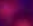

5

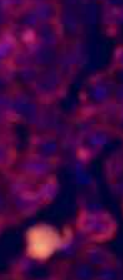
6. 325 $i^{2}+x^{2}$

20

- Of

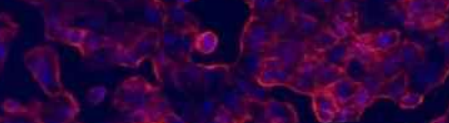

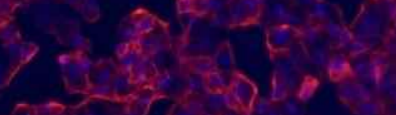

$\sin 8$

(

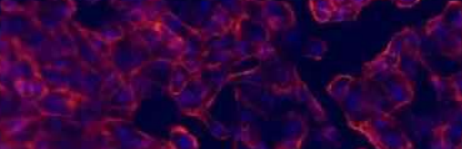

405

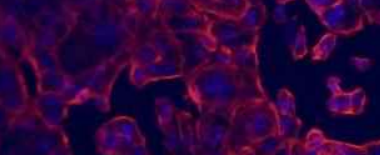

$60^{\circ}$ a.

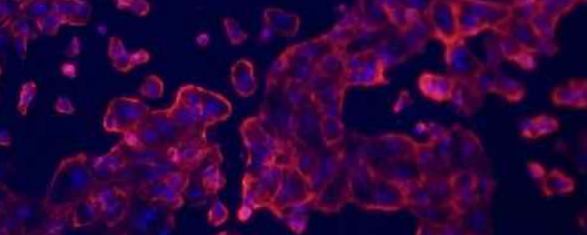




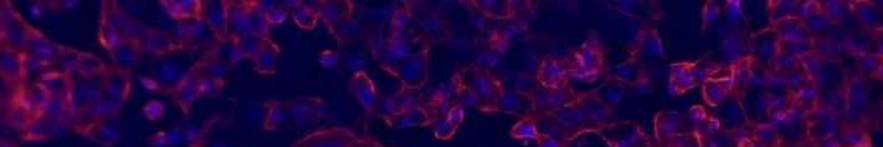


Control 


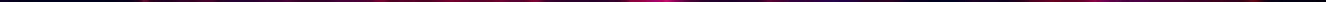


ALN $0.1 \mu \mathrm{M}$ 


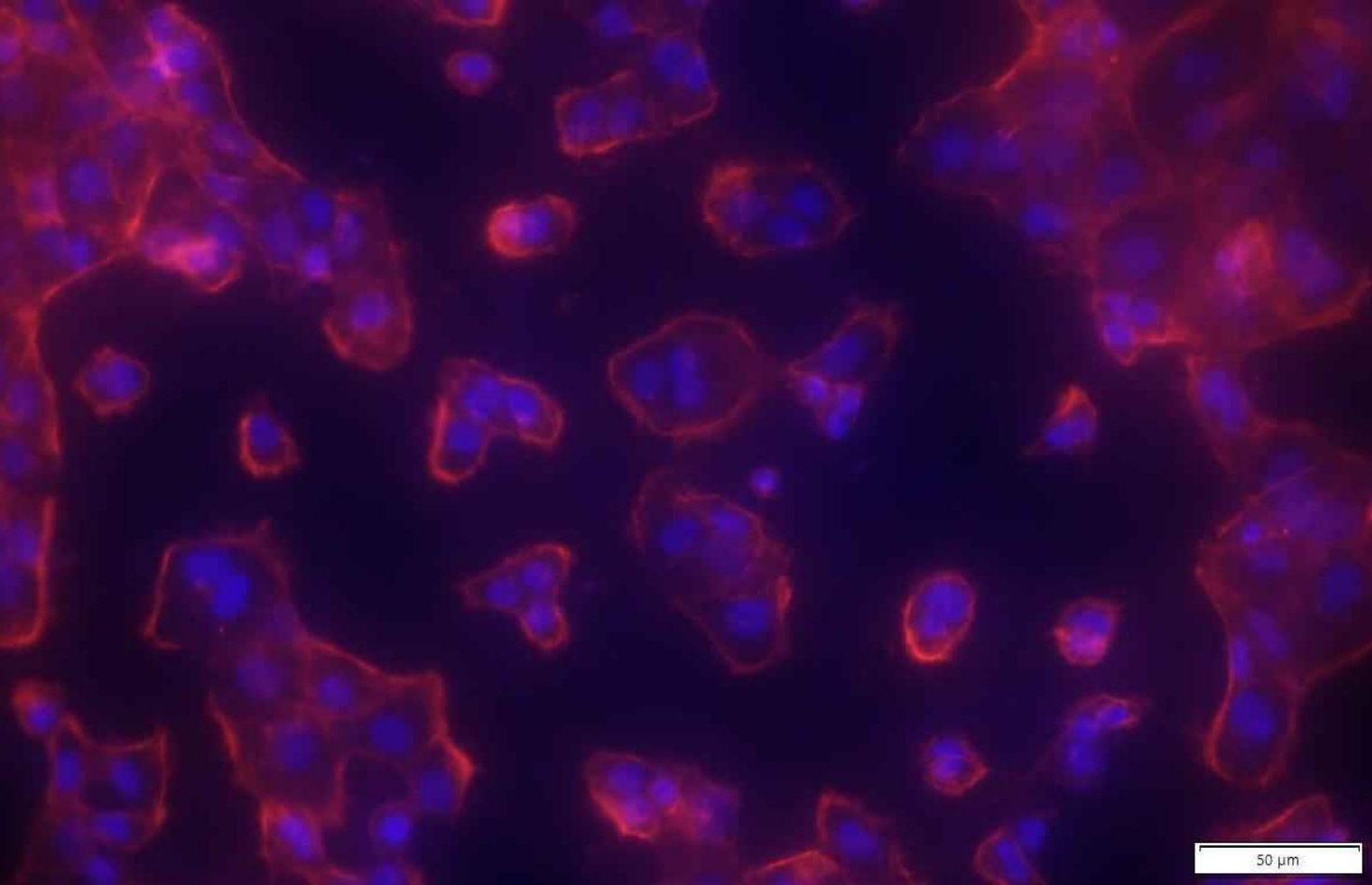


ALN $0.2 \mu \mathrm{M}$

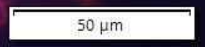





\section{$\mathrm{ZA} 0.5 \mu \mathrm{M}$}




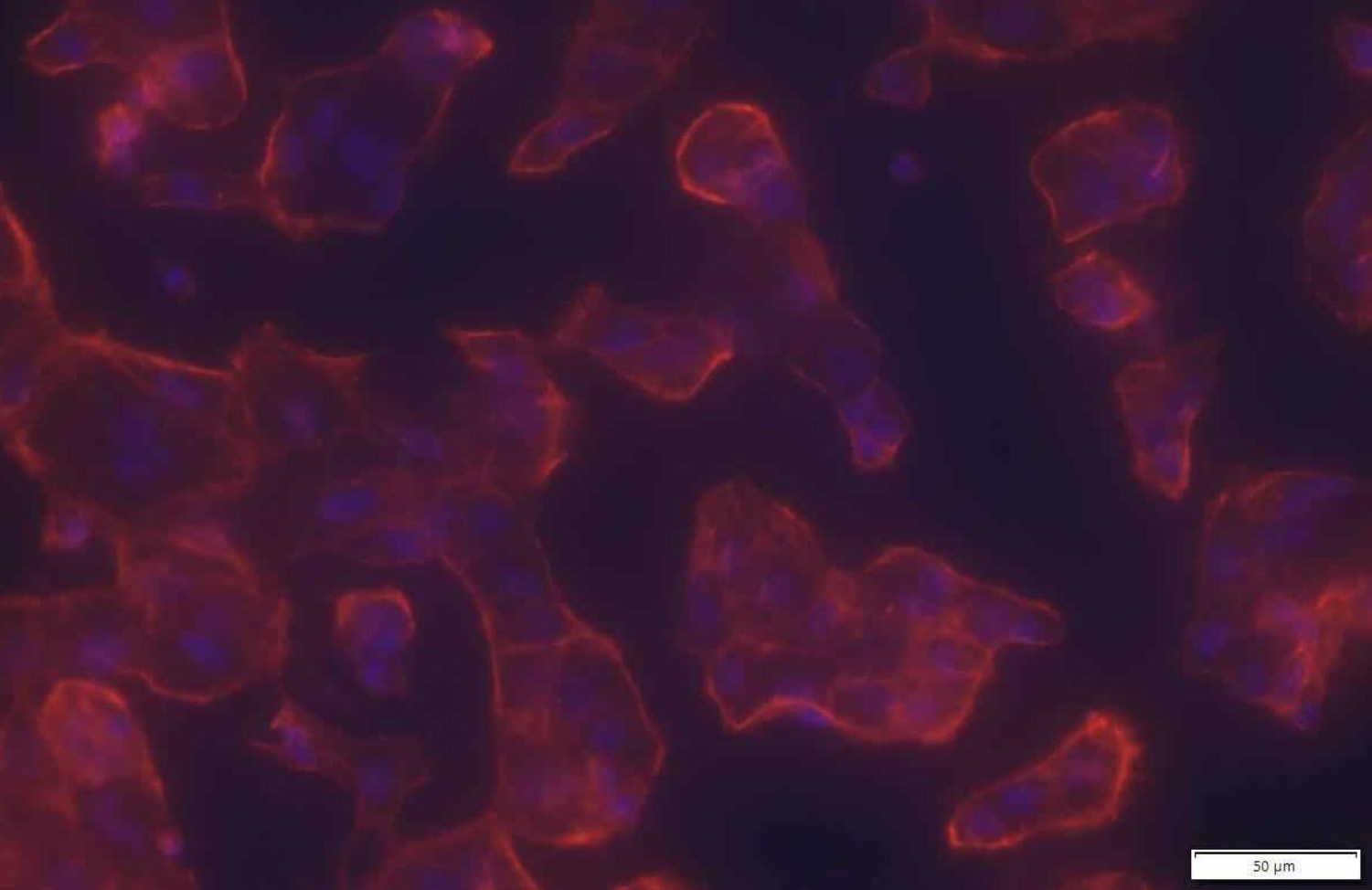


$\mathrm{ZA} 1 \mu \mathrm{M}$

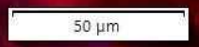




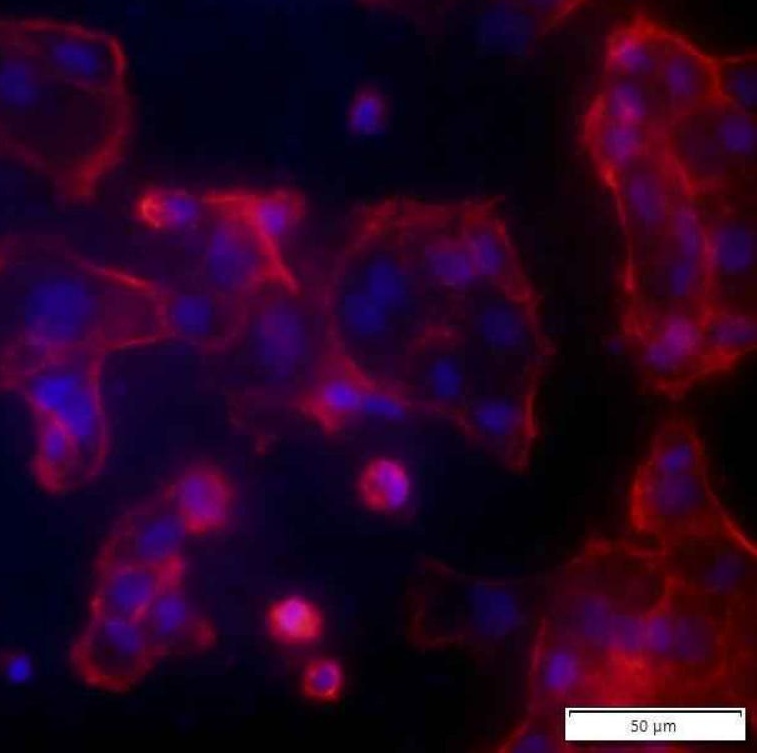




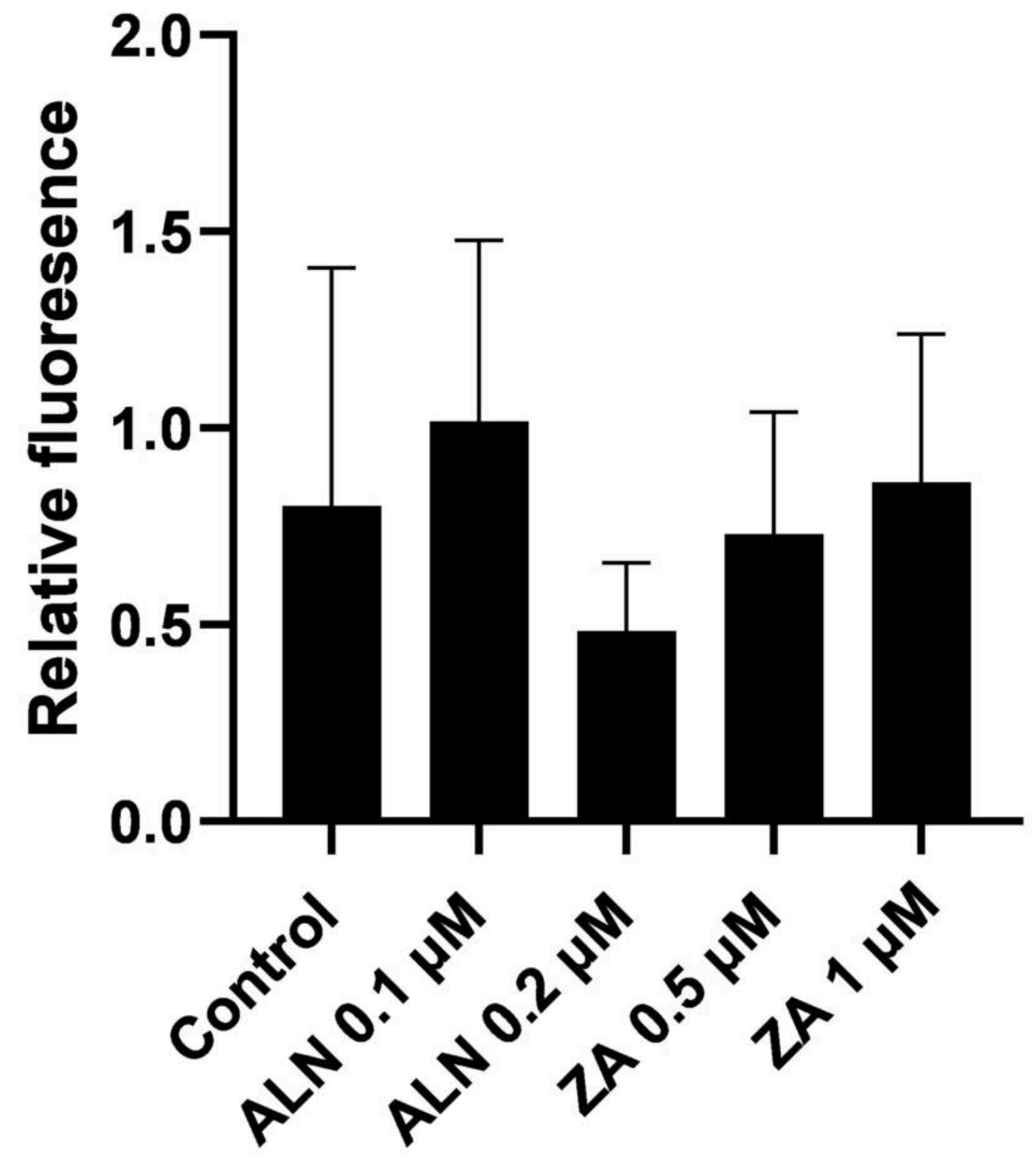




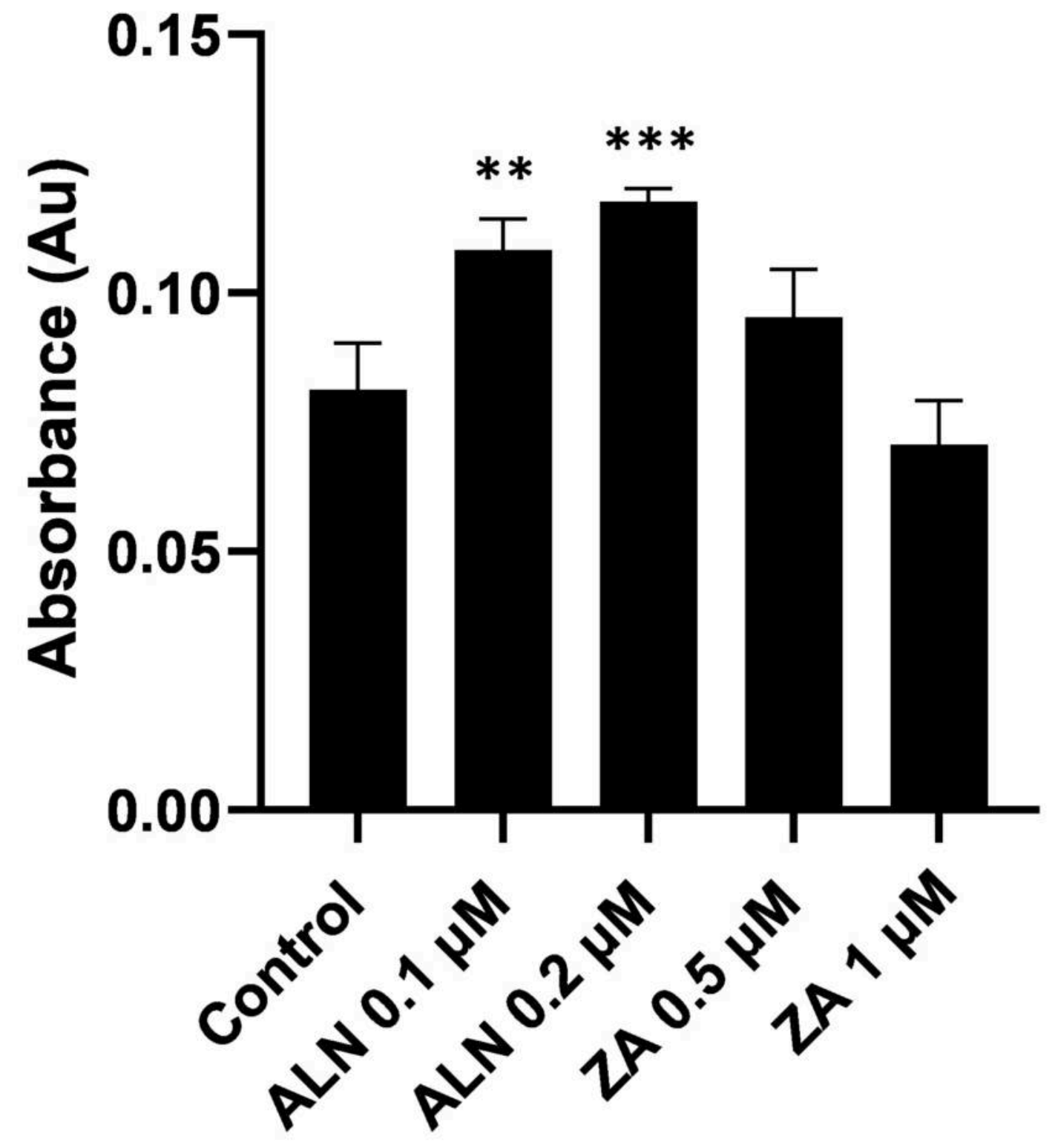




\begin{tabular}{|ll|}
\hline Drug & Concentration \\
\hline Control & N/A \\
\hline ALN & a) $0.1 \mu \mathrm{M}$ \\
& b) $0.2 \mu \mathrm{M}$ (Therapeutic dose) ${ }^{11}$ \\
\hline ZA & a) $0.5 \mu \mathrm{M}$ \\
& b) $1 \mu \mathrm{M}$ (Therapeutic dose) ${ }^{12}$ \\
\hline
\end{tabular}

